\title{
Progress Report on the Evaluation of Porous Cathode for the Electrochemical Reduction of Nitrates and Nitrites in Liquid Wastes
}

by
D. T. Hobbs

Westinghouse Savannah River Company

Savannah River Site

Aiken, South Carolina 29808

K. tha

Dept of Chem Eng, Univ of South Carolina

SC USA

J. W. Weidner

Dept of Chem Eng, Univ of South Carolina

SC USA

R. E. White

Dept of Chem Eng, Univ of South Carolina SC USA

DOE Contract No. DE-AC09-89SR18035

This paper was prepared in connection with work done under the above contract number with the U.S.

Department of Energy. By acceptance of this paper, the publisher and/or recipient acknowledges the U.S. Government's right to retain a nonexclusive, royalty-free license in and to any copyright covering this paper, along with the right to reproduce and to authorize others to reproduce all or part of the copyrighted paper. 


\section{DISCLAIMER}

This report was prepared as an account of work sponsored by an agency of the United States Government. Neither the United States Government nor any agency thereof, nor any of their employees, makes any warranty, express or implied, or assumes any legal liability or responsibility for the accuracy, completeness, or usefulness of any information, apparatus, product, or process disclosed, or represents that its use would not infringe privately owned rights. Reference herein to any specific commercial product, process, or service by trade name, trademark, manufacturer, or otherwise does not necessarily constitute or imply its endorsement, recommendation, or favoring by the United States Government or any agency thereof. The views and opinions of authors expressed herein do not necessarily state or reflect those of the United States Government or any agency thereof.

This report has been reproduced directly from the best available copy.

Available to DOE and DOE contractors from the Office of Scientific and Technical Information, P.O. Box 62, Oak Ridge, TN 37831; prices available from (615) 576-8401.

Available to the public from the National Technical Information Service, U.S. Department of Commerce, 5285 Port Royal Road, Springfield, VA 22161. 


\section{DISCLAIMER}

Portions of this document may be illegible in electronic image products. Images are produced from the best available original document. 
Distribution:

T. B. Fryberger, DOE-HQ

W. L. Kuhn, PNL

W. E. Lawrence, PNL

R. E. White, USC

A. M. Blackmon, DOE-SR, 703-A

M. Schwenker, DOE-SR, 703-H

L. M. Papouchado, 773-A

C. R. Wolfe, 773-A

H. D. Harmon, 719-4A

W. L. Tamosaitis, 773-A

S. D. Fink, 773-A

J. L. Steimke, 786-5A

D. T. Hobbs, 773-A

J. T. Coleman, 773-41A

A. Patterson, 773-A

TIM, 773-52A 
WSRC-TR-95-0438

Keywords: Electrolysis, Alkaline, Salt Solution, Modeling, Waste Management,

Retention time: permanent

September 26, 1995

TO:

S. D. Fink, 773-A

DTH

FROM:“ D. T. Hobbs, 773-A

\section{Progress Report on the Evaluation of Porous Cathode for the Electrochemical Reduction of Nitrates and Nitrites in Liquid Wastes (u)}

Attached is a report prepared by the Department of Chemical Engineering, University of South Carolina under contract \#AA00900T, Task \#112 investigating the use of porous electrode technology for the electrochemical reduction of nitrate and nitrite from alkaline waste solution. This report fulfills milestone E.2. of Technical Task Plan SR1-3-20-05, revision 0, "Electrochemical Destruction of Nitrates and Organics."

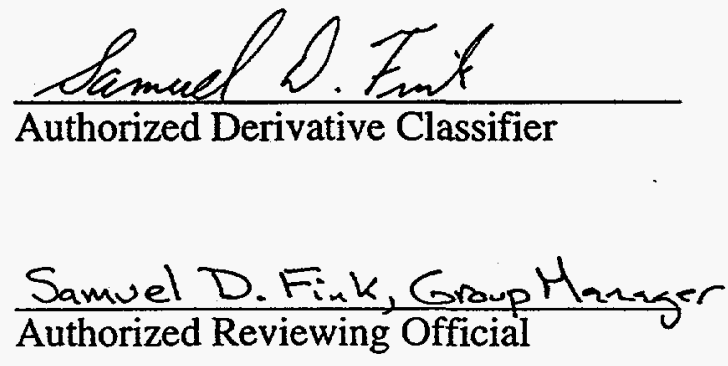

Savannah River Technology Center

Westinghouse Savannah River Company

Aiken, SC 29802

Prepared for the Department of Energy Office of Technology Development, Office of Environmental Management under Contract DE-AC09-88SR18035 
EVALUATION OF A POROUS CATHODE USED FOR THE ELECTROCHEMICAL REDUCTION OF NITRATES AND NITRITES IN LIQUID WASTES

A Milestone Report submitted to

Dr. David T. Hobbs

Westinghouse Savannah River Company

By

Kamal Jha, John W. Weidner and Ralph E. White

Department of Chemical Engineering

University of South Carolina

Columbia, SC 29208

December 27, 1995 


\section{Abstract}

This report describes the experimental and modeling work performed to evaluate porous cathodes for the electrochemical reduction of nitrates and nitrites in liquid wastes. The experiments were done using the $\mathrm{MP}^{\dagger}$ cell with two different porous cathodes: nickel foam and $\mathrm{TySAR}^{\mathrm{TM}} \mathrm{SB}^{\ddagger}$. The experimental results are compared with each other and to those obtained with a planar nickel cathode. The results show that the ammonia production reaction is the dominant cathodic reaction ( $\sim 80 \%$ efficiency) for all three electrodes. The temperature range used in this study was $29-37^{\circ} \mathrm{C}$ while the catholyte feed was either $0.6 \mathrm{M} \mathrm{NaNO}$ or $1.9 \mathrm{M} \mathrm{NaNO}$, both supported by a $1.33 \mathrm{M} \mathrm{NaOH}$ solution. All experiments used a constant current density of $0.25 \mathrm{~A} / \mathrm{cm}^{2}$. The experimental results suggest that the porous nickel electrode at lower temperatures $\left(-31^{\circ} \mathrm{C}\right)$ is the most efficient of the three eleetrodes for-the reduction of nitrates and-nitrites.-The porous nickel electrode exhibited the highest conversion of nitrates and nitrites, and the lowest overpotential for a given current density.

The partial current fractions at known catholyte concentrations were used to extract the exchange-current densities for the five cathodic reactions. Using these kinetic parameters, dynamic simulations of the four hour experiments were performed. Agreement was found between the model and experimental results for changes in the moles of the nitrate and nitrite and the cell overpotential with time. Future work will determine the effects of temperature and current densities on the exchange-current densities and reaction product distributions. The performance of other porous cathode materials $\left(\mathrm{TySAR}^{\mathrm{TM}} \mathrm{EP}^{\S}\right.$, $\operatorname{TySAR}^{\mathrm{TM}} \mathrm{IM}^{* *}$ ) will also be evaluated.

\section{Introduction}

Electrochemical treatment of hazardous wastes has been a topic of active research. Removal and recovery of heavy metals from dilute waste streams ${ }^{1-7}$ and destruction and removal of cyanide wastes from electroplating baths ${ }^{8}$ are examples of specific research areas. Electrochemical treatment of wastes has been improved through the use of porous electrodes due to the high reaction area and enhanced mass transfer rates provided in this configuration. Higher surface area increases the reaction rates and, therefore, reduces the number of cells required to treat a fixed amount of waste. In the metal removal and recovery applications, flow-through porous electrodes have been particularly effective in

\footnotetext{
${ }^{\dagger}$ Multi-purpose electrochemical cell developed by Electrocell AB (Sweden).

${ }^{\ddagger}$ High surface area titanium fiber porous electrode developed by Olin Corporation (Charleston Technology Center, Charleston, TN).

${ }^{\S}$ High surface area platinum loaded porous electrode developed by Olin Corporation.

"* High surface area proprietary intermetallic catalyst loaded porous electrode developed by Olin Corporation.
} 
electrowinning of relatively noble metals (e.g., $\mathrm{Cu}$ ) where no gas bubbles are generated within the electrode. ${ }^{2,6}$ However the electrowinning of non-noble metals (e.g., $\mathrm{Zn}, \mathrm{Cr}$ ) using the porous electrodes requires different design and operating considerations since the inevitable generation of hydrogen gas bubbles within the pores can render the electrode inoperable. A loss of processing efficiency occurs as a result of the accumulation of gas bubbles in the porous matrix leading to a significant decrease in the pore electrolyte conductivity.,

The present work involves the treatment of wastes produced from nuclear materials production within the Department of Energy. A tentative flowsheet for the overall process at the Savannah River Site is as shown in Figure 1. It consists of the InTank Precipitation Facility (ITP), an electrochemical reactor, off-gas processing and evap.orator/crystallizer units..The. ITP. removes greater than $99.5 \%$.of radioactivity from the high level wastes, which are then immobilized in a borosilicate glass wasteform. The remaining low-level radioactive waste contains many hazardous substances among which nitrates and nitrites are present in the highest concentration. Significant savings in waste disposal costs may be possible by destroying the nitrates and nitrites. The key unit of this flowsheet is the electrochemical reactor. The reactor used in the current work is a divided cell having a porous cathode, a cation selective separator and a planar anode.

Previous experimental work has shown the electrochemical reduction to be an effective treatment of nitrate and nitrite waste solutions. ${ }^{9,10,11,12}$ Hobbs and Ebra ${ }^{9}$ demonstrated the feasibility of electrolytically reducing nitrate and nitrite in an undivided or a divided cell with a planar nickel cathode and a feed solution simulating that produced at the Savannah River Site. High destruction ( $99 \%)$ of nitrates and nitrites were obtained in a batch process with the products being ammonia, nitrogen, oxygen and sodium hydroxide. However, even in the divided cell, the per pass conversion is small ${ }^{10}$ due to slow kinetics. Therefore, using a cathode having a higher reaction area such as a porous cathode should increase the per pass conversion. $\mathrm{Li}$ et al. ${ }^{11}$ extended this work by studying the nitrate and nitrite reduction as a function of electrode material, temperature and solution composition. They found that electrolysis of $\mathrm{NaNO}_{3}$ in $3 \mathrm{M} \mathrm{NaOH}$ and 0.25 $\mathrm{Na}_{2} \mathrm{CO}_{3}$ at $80^{\circ} \mathrm{C}$ using platinized nickel planar electrodes resulted in a highly efficient reduction process with nitrogen and ammonia being the main products at lower $(0.1$ $\left.\mathrm{A} / \mathrm{cm}^{2}\right)$ and higher $\left(0.4 \mathrm{~A} / \mathrm{cm}^{2}\right)$ current densities, respectively.

The modeling of the nitrate/nitrite waste system has been done by Coleman et al. ${ }^{13}$ and Prasad et al. ${ }^{14}$ for a parallel-plate electrochemical reactor system. Coleman ${ }^{13}$ used a divided cell model with a porous non-selective membrane for this multiple reaction system to predict current efficiencies and outlet concentrations of species from the reactor, given the inlet feed and cell operating conditions. Predictions for off-gas and liquid compositions in recirculation tanks (see Figure 2) were also made. The model predictions showed that although the destruction efficiency is higher at lower potentials, the time required to destroy a given amount of waste is also large. The lower efficiencies at higher potentials were due to: (i) repulsion of the negatively charged nitrate and nitrite ions from the catholyte due to migration and, thus, depletion of this reactant at the cathode, and (ii) an 
increase in undesired hydrogen evolution reaction due to higher overpotential. The governing equations were solved in two dimensions and, although the method was rigorous and exact, it was also computationally intensive. To increase the computational efficiency of the model, Prasad ${ }^{14}$ modified the model by assuming that the concentration gradients in the catholyte and anolyte existed only in a thin boundary layer near the respective electrodes. The concentration in the solution outside these layers was assumed constant and equal to the bulk values. This assumption was shown to be valid as the results from the two models agree over a wide range of applied currents. In addition to the computational efficiency, the second advantage of Prasad's model is that it was written using SPEEDUP ${ }^{\mathrm{TM} \dagger t}$. The use of SPEEDUP ${ }^{\mathrm{TM}}$ facilitated the use of rigorous thermodynamics for flash calculations by giving access to Properties Plus, Aspen Technology's physical-properties database. The model developed by Prasad ${ }^{14}$ has been used for optimization studies on the parallel plate reactor for the treatment of nitrate/nitrite wastes.

We used the boundary-layer approximation in the modeling the nitrate and nitrite reduction at a porous cathode. ${ }^{15}$ The same approximation was used by Saleh et al. ${ }^{7}$ to model the electrowinning of zinc in porous electrodes. The electrowinning of zinc is similar to the system presented here as hydrogen evolution is present as an unavoidable side reaction. Their model simulations indicated that high flow rates (resulting in low single pass conversion) are required to minimize the ohmic resistance due to gas evolution. The reduction of nitrate and nitrite however, differs from the reduction of zinc in three important ways: (i) there are four reactions competing with the hydrogen evolution reaction compared to one; (ii) three of the main reactions have gaseous products (i.e., $\mathrm{NH}_{3}$ $\mathrm{N}_{2}, \mathrm{~N}_{2} \mathrm{O}$ ), of which ammonia is highly soluble; and (iii) the negatively charged nitrate and nitrite ions are repelled from the cathode thus increasing the mass-transfer resistance to the electrode surface.

The results we presented previously ${ }^{15}$ indicated that the optimum current from a porous cathode could be ten times higher than that from a planar electrode. The increased current means that up to ten times fewer cells would be required to treat a quantity of waste if porous cathodes were used. The exact number, however, depends on the kinetics of the five competing reactions. Therefore, one of the objectives of this study was to use the model to determine the kinetic parameters of the cathodes. These parameters can then be used in the model to determine the optimum cell current for each material.

A second objective of this study was to evaluate batch data using various porous electrode materials. In this report, the experimental results obtained using two porous cathodes are presented and compared to those obtained for a planar one. The batch experiments were done using the different cathodes, feeds and temperatures ( see Table 3) at constant current $(25 \mathrm{~A})$. All the runs used a divided MP cell, with Nafion ${ }^{\otimes}$ as separator, and 2-3M sodium hydroxide $(\mathrm{NaOH})$ solution as the anolyte feed. The concentration of the reactants and products in the liquid and gas phases were measured along with the catholyte volume and off-gas flowrate. These measurements were used to calculate the

"t Aspen Technology's dynamic flowsheet simulator software. 
current fractions of the different cathodic reactions and moles of nitrate and nitrite destroyed.

Simulations were fit to the partial current fractions obtained from the porous nickel foam cathode by adjusting the exchange-current densities. ${ }^{\ddagger t}$ Model predictions of the cell potential and moles of nitrate and nitrite destroyed were found consistent with the experimental data. Similar experimental and model simulation studies on other porous cathodes $\left(\right.$ TySAR $^{\mathrm{TM}} \mathrm{EP}, \mathrm{TySAR}^{\mathrm{TM}} \mathrm{IM}$ ) are planned for future.

\section{Electrochemical Reactor Model}

The objective of the reactor is to destroy or remove the hazardous species (i.e. nitrates and nitrites) from the waste solution by reducing them to gases such as nitrogen, ammonia and nitrous oxide. The main reactions presumed to be occurring inside the electrochemical reactor are given below:

$$
\begin{array}{cc}
\text { Reaction } & \mathrm{U}^{\theta}(\mathrm{V}) \\
\mathrm{NO}_{3}^{-}+\mathrm{H}_{2} \mathrm{O}_{(l)}+2 e^{-} \rightarrow \mathrm{NO}_{2}^{-}+2 \mathrm{OH}^{-} & 0.01 \\
\mathrm{NO}_{2}^{-}+5 \mathrm{H}_{2} \mathrm{O}_{(l)}+6 e^{-} \rightarrow \mathrm{NH}_{3(g)}+7 \mathrm{OH}^{-} & -0.165 \\
2 \mathrm{NO}_{2}^{-}+4 \mathrm{H}_{2} \mathrm{O}_{(l)}+6 e^{-} \rightarrow \mathrm{N}_{2}(\mathrm{~g})+8 \mathrm{OH}^{-} & 0.406 \\
2 \mathrm{NO}_{2}^{-}-3 \mathrm{H}_{2} \mathrm{O}_{(l)}+4 e^{-} \rightarrow \mathrm{N}_{2} \mathrm{O}_{(\mathrm{g})}+6 \mathrm{OH}^{-} & 0.15 \\
2 \mathrm{H}_{2} \mathrm{O}_{(l)}+2 e^{-} \rightarrow \mathrm{H}_{2(g)}+2 \mathrm{OH}^{-} & \\
4 \mathrm{OH}^{-} \rightarrow \mathrm{O}_{2}(\mathrm{~g}) & \\
&
\end{array}
$$

Reactions (1)- (5) occur at the cathode and reactions (6) and (7) at the anode. All the above reactions can be written in the following general format:

$$
\sum_{i} s_{i j} M_{i}^{z_{i}} \rightarrow n_{j} e^{-}
$$

¥t A kinetic parameter which is equal to the forward and backward currents present at equilibrium under reference conditions ${ }^{16}$. 
In this format, the stoichiometric coefficient $s_{i j}$ is positive for products and negative for reactants when the reaction is written as a reduction.

A schematic of the MP cell modeled in this work is shown in Figure 3. It is a divided cell with a porous cathode, a planar anode and a cation selective separator. The divided cell system is preferred over the undivided cell to minimize the oxidation of nitrites to nitrates at the anode (equation 7). The separator also prevents the formation of a flammable mixture of ammonia, hydrogen and oxygen.

\section{Assumptions}

The assumptions valid for all the components of the cell follow:

1. The dynamics of the reactor are neglected in the presence of recirculation tank dynamics (see Figure 2 for the batch system).

2. No homogeneous chemical reactions occur in the reactor.

3. Dilute solution theory applies.

4. The Nernst - Einstein equation $\left(\mathrm{u}_{\mathrm{i}}=\mathrm{D}_{\mathrm{i}} / \mathfrak{R T}\right)$ applies.

5. The Butler-Volmer equation can be used to describe the reactions at the electrode surface.

6. Isothermal conditions exist.

7. The bulk solution conductivity is uniform in each of the anolyte, catholyte, and separator regions.

8. The physical transport parameters are constant.

9. Density of the process stream remains constant.

10. Concentration of gases in the anolyte stream is low.

Assumption 1 is valid because the volume of the reactor is small compared to the recirculation tank and the per pass conversion in the reactor is also low. Assumptions 2 through 6 are common to most porous/parallel-plate electrochemical reactor models. Assumption 7 arises from the fact that the conductivity is a function of the sum of the species concentrations which remains almost unchanged (since all the species in the simulated waste carry unit charges and electroneutrality is maintained). Assumptions 8 through 10 are common in reactor modeling. Assumption 10 is based on results from preliminary studies. ${ }^{9.12}$ 
The models of the different cell components (i.e., the porous cathode, separator and the planar anode) follow:

\section{Porous Cathode}

Figure 3 shows a magnified view of the porous electrode region. The current densities encountered in the model are of two kinds: solution current density $(i)$ and reaction current densities $\left(\mathrm{j}_{\mathrm{j}}, \mathrm{j}=1 . .5\right)$. The solution current density is the current carried by the ions in the solution and is based on the superficial cross-sectional area. The reaction current densities are the interfacial currents at the metal-liquid interface and are based on the interfacial area. They are the result of the electron exchange taking place at the interface. Additional assumptions pertaining to the porous cathode follow:

11. The porous cathode matrix has uniform volume average properties such as porosity $(\theta)$, tortuosity $(\tau)$ and interfacial area per volume (a). It also has a very high electronic conductivity compared to that of the electrolyte, such that the potential within the metal matrix is uniform. The matrix is assumed to be insoluble in the electrolyte.

12. The solution potential and current vary only in the axial direction of flow.

13. The thickness of the diffusion layer formed inside the pores of the cathode is constant throughout the electrode and is not affected by the generation of gas bubbles.

14. There are negligible changes in the bulk concentration of the reactants in the direction of convective flow (due to low single-pass conversion).

15. The electrolyte flowrates are high and sweep all the gas bubbles out of the pores.

16. Ammonia concentration in the catholyte is assumed to be less than the saturation limit. Therefore, it dissolves as soon as it is produced. Modifications are being made in the model to account for conditions at which the ammonia concentration reaches the saturation limit and the ammonia produced remains in gas phase.

The above assumptions are used to develop the basic equations ${ }^{17}$ for the porous cathode model as given below. The solution current $(i)$ is related to the interfacial reaction currents $\left(\mathrm{j}_{\mathrm{j}}\right)$ as follows:

$$
\frac{d i}{d x}=a \sum_{j}^{5} j_{j}
$$

The Butler - Volmer equation gives a correlation between the interfacial current density $(\mathrm{j} j)$ and the reference overpotential $\left(\eta_{r e f, j}\right)$. 


$$
j_{j}=i_{o, r e f, j}\left[\prod_{i}\left(\frac{C_{i, s, c}}{C_{i, b, c}}\right)^{p_{i j}}\left(\frac{C_{i, b, c}}{C_{i, r e f}}\right)^{p_{i j}} e^{\alpha_{\alpha j} n f \eta_{r s}, J}-\prod_{i}\left(\frac{C_{i, s, c}}{C_{i, b, c}}\right)^{q_{i j}} \cdot\left(\frac{C_{i, b, c}}{C_{i, \text { ref }}}\right)^{q_{i j}} e^{-\alpha_{g j} n f \eta_{r e f, j}}\right]
$$

where, $\quad \eta_{\text {ref }, j}=V_{c}-\phi_{c}-U_{r e f, j} \quad$ for reactions at the cathode

$$
U_{r e f, j}=U_{j}^{\theta}-\frac{1}{n_{j} f} \sum_{i} s_{i j} \ln C_{i, r e f, j}
$$

and,

$$
p_{i j}=s_{i j}, q_{i j}=0 \text { if } s_{i j}>0 ; p_{i j}=0, q_{i j}=-s_{i j} \text { if } s_{i j}<0
$$

Prasad $^{14}$ has derived an expression for the ratio of the concentration of a reacting species at the surface $\left(\mathrm{C}_{\mathrm{i}, \mathrm{s}, \mathrm{c}}\right)$ to that at the bulk $\left(\mathrm{C}_{\mathrm{i}, \mathrm{b.c}}\right)$ using the boundary layer assumption which for the cathode section gives the following relation:

$$
\frac{C_{i, s, c}}{C_{i, b, c}}=\left(\frac{N_{i}}{D_{i} \gamma_{i} C_{i, b, c}}\right)+\left(1-\frac{N_{i}}{D_{i} \gamma_{i} C_{i, b, c}}\right) e^{\gamma_{1} \delta}
$$

where,

$$
\gamma_{\mathrm{i}}=\frac{z_{\mathrm{i}} \mathrm{Fj}_{\mathrm{t}}}{\mathfrak{R T K}}
$$

and

$$
\mathrm{j}_{\mathrm{t}}=-\sum_{\mathrm{j}} \mathrm{j}_{\mathrm{j}}
$$

Ohm's law relates the solution current $(i)$ to the axial potential gradient as follows:

$$
i=-\kappa_{e f f} \frac{d \phi_{c}}{d z}
$$

where

$$
\kappa_{e f f}=\kappa_{c}\left(\theta-\theta_{g}\right)^{1.5}
$$

and $\kappa_{c}=\frac{F^{2}}{\mathfrak{R} T} \sum_{i} z_{i}^{2} D_{i} C_{i, b, c}$

The gradient of the gas porosity is related to the gas producing reaction currents as:

$$
\frac{d \theta_{g}}{d z}=a\left(\frac{\mathfrak{R} T\left(\theta-\theta_{g}\right)^{2}}{P F Q \theta}\right) \sum_{3}^{5} \frac{j_{j}}{n_{j}}
$$

In the above equation ammonia reaction current $\left(\mathrm{j}_{2}\right)$ is not considered due to assumption (16). 
The boundary conditions at the electrode edge closest to the anode (i.e., $z=0$ ) are:

$i=i$ cell and equations $(9-14,16,17)$ are valid.

The boundary conditions at the electrode edge farthest away from the anode (i.e., $z=L$ ) are:

$\mathrm{i}=0$,
$\frac{\mathrm{d} \phi_{\mathrm{c}}}{\mathrm{dz}}=0$,

$\theta_{\mathrm{g}}=0$, and

equations (9-14) are valid.

The cathode model is the major component of the electrochemical cell model. This is because of the large number of reactions and species present in the cathode section.

\section{Separator}

Both diffusion and migration contribute to the flux of species "i" through the separator and, therefore, the flux is given by,

$$
N_{i}=-D_{i} \frac{d C_{i}}{d x}-\frac{z_{i} D_{i} F}{\mathfrak{R} T} C_{i} \frac{d \phi}{d x}
$$

Assuming the potential drop across the separator to be linear an equation analogous to equation (13) can be written for the flux of species " $i$ " across the separator, as follows,

$$
N_{i, s}=-D_{i, e} \frac{d C_{i}}{d x}+\frac{z_{i} D_{i, e} F}{\Re T} \frac{i_{t}}{\kappa_{s}} C_{i}
$$

Integrating equation (21) by using the known concentrations on both sides of the separator and rearranging gives,

$$
N_{i, s}=\left[\frac{C_{i, b, a}}{C_{i, b, c}}-e^{\gamma_{i, s} \delta_{s}}\right] *\left[\frac{D_{i, e} \gamma_{i, s} C_{i, b, c}}{1-e^{\gamma_{i, s} \delta_{s}}}\right]
$$

where, $\quad D_{i, e}=\frac{D_{i}}{N_{m}} \quad$ and $\quad \gamma_{i, s}=\frac{z_{i} F i_{t}}{\mathfrak{R T} \kappa_{s}}$

where, $\quad \kappa_{s}=\frac{F^{2}}{2 \mathfrak{g R T}} \sum_{i} z_{i}^{2} D_{i, e}\left(C_{i, b, c}+C_{i, b, a}\right) N_{m}$. 
The separator used in this study was permeable to only cationic species. The effective diffusion coefficient and the conductivity are characterized by a MacMullin number, ${ }^{18} N_{m}$ (see Table 4 for values), which is a function of the separator's porosity and tortuosity.

\section{Planar Anode}

The Butler-Volmer rate expression is used to relate the partial current $\left(i_{j}\right)$ associated with reaction " $\mathrm{j}$ " to the surface concentration $\left(C_{i, s, a}\right)$ of species " $\mathrm{i}$ " and the overpotential $\left(\eta_{j}\right)$ for reaction " $\mathrm{j}$ " as follows:

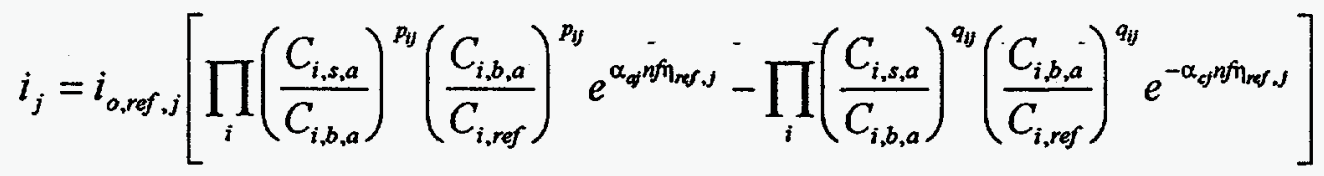

where

$$
\eta_{r e f, j}=V_{a}-\phi_{a}-U_{r e f, j} \text { for reactions at the anode }
$$

Values for $U_{\text {refj, }}, \mathrm{p}_{\mathrm{ij}}$ and $\mathrm{q}_{\mathrm{ij}}$ are calculated using a method similar to one used for the cathode section. The expression relating $\phi_{c o}$ (i.e. overpotential in the cathode at $z=0$ in Figure 3) and $\phi_{a}$ (based on the constant voltage drop assumption) is as given below:

$$
\phi_{a}=\phi_{c 0}+i_{t} A R_{c e l l}
$$

where, $\quad R_{\text {cell }}=\frac{l}{A}\left(\frac{S_{a}}{\kappa_{a}}+\frac{S_{s} N_{m}}{\kappa_{s}}+\frac{S_{c}}{\kappa_{c}}\right)$

and

$$
\kappa_{a}=\frac{F^{2}}{\mathfrak{R} T} \sum_{i} z_{i}^{2} D_{i} C_{i, b, a}
$$

The ratio of the concentration of a reacting species at the surface $\left(\mathrm{C}_{\mathrm{i}, \mathrm{s}, \mathrm{a}}\right)$ to that at the bulk $\left(\mathrm{C}_{\mathrm{i}, \mathrm{b}, \mathrm{a}}\right)$ is calculated by using the boundary-layer assumption. An expression analogous to equation (12) is obtained with the cell current $\left(i_{c e l l}\right)$ replacing the total interfacial current $\left(j_{i}\right)$ in the calculation for the parameter $\gamma_{i}$ in equation (13).

\section{Solution Procedure}

The porous cathode model equations (i.e., 9-17) were solved using a finite difference subroutine $B a n d(j)^{I 7}$. The reaction currents are then integrated using Simpson's rule $^{19}$ to get the distribution of the solution current in the five reactions taking place. The porous cathode model can be used independently to get the cathodic current efficiencies 
and the required overpotential, given a cell current, catholyte feed composition, temperature and flowrate. However for a batch simulation, in which the concentration of the reactants change with time, the complete cell model (i.e., cathode, separator and anode) is needed to track the dynamics of the cell or process units connected with the cell in the batch process flowsheet.

The anode and separator models have been developed earlier by Prasad ${ }^{14}$ and are programmed in SPEEDUP ${ }^{\mathrm{TM}}$, while the porous cathode model is written in FORTRAN. These three reactor section models are linked using a FORTRAN/SPEEDUP ${ }^{\text {TM }}$ interface to give the porous electrochemical cell model.

The experiments done on the cell were batch processes using the setup shown in Figure 2. It consisted of a divided cell, two continuously recycling streams (anolyte and catholyte) and two recirculation tanks (one each for the two streams) which can treated as batch reactors with gas generation (see assumption 1). The model for the overall batch system for the parallel plate electrochemical reactor has been developed by Prasad ${ }^{14}$ which includes models for the recirculation/flash tanks. Therefore, the model for the batch system used in the present work is obtained by modifying Prasad's model to incorporate the porous electrochemical reactor.

\section{Experimental}

A schematic diagram of the testing equipment used for the experimental runs is shown in Figure 2. A divided MP cell was used with Nafion ${ }^{\otimes}$ membrane as the separator. The membrane is cation selective, and therefore, care was taken to face a particular side of the membrane towards the catholyte. The cell was assembled so that the porous cathode is in the flow-through mode and the planar anode is in the flow-by mode. Flowrates and the temperatures of the anolyte and catholyte streams were controlled.

The purpose of the recirculation tank was to thoroughly mix the incoming process stream with the reservoir contents. The off gas from the catholyte recirculation tank were passed through a water condenser to remove the water vapor in the gases. The rate of generation of gaseous products from the catholyte was very small. To measure the production rate, the off gas was purged continuously with a known and constant inert gas (Argon) flow. This yielded a measurable flow. The molar flowrates of the gaseous products were calculated using the volume percent of the individual gases and total off-gas flowrate.

Samples of the off gas, catholyte and anolyte were taken at fixed time intervals (30 mins). Also at these sampling times, the values for the potentials in the three cell compartments (i.e., anode, separator and cathode), with respect to the reference electrodes $(\mathrm{Ag} / \mathrm{AgCl})$ were recorded along with the overall cell potential and current. The 
reference electrode in the cathode section was placed between the separator and the porous cathode and, therefore, it measured the maximum cathodic overpotential.

All experiments used a stainless steel planar anode and a 2-3M NaOH anolyte feed solution. There was negligible nitrite concentration in the anolyte feed. Also due to a cationic selective separator, there was negligible transport of nitrite from the catholyte. Therefore, the nitrite oxidation reaction (equation 7) was negligible and oxygen evolution was the predominant anodic reaction. For the 4 hour batch runs, a hydroxide concentration of $2-3 \mathrm{M} \mathrm{NaOH}$ was adequate to ensure that the oxygen generation reaction is not mass transfer limited. Two porous cathodes were used: (i) nickel foam, and

(ii) TySAR ${ }^{\mathrm{TM}} \mathrm{SB}$. The thickness and porosity of these electrodes are shown in Table 4. These measurements were performed as follows:

(i) A rectangular strip $(10.0 \mathrm{~cm} \times 1.5 \mathrm{~cm})$ was cut from a sheet of the porous cathode material. The thickness of the cathode strip was measured by a Mitutoyo ${ }^{\text {TM }}$ dial thickness gage (see Table 4).

(ii) The strip was dipped completely in a glass vessel filled with water to an initial known level $(-100 \mathrm{ml})$ and a vacuum was applied to the jar to drive out the air trapped in the pores of the porous material. When air bubbles stopped coming out of the cathode strip, the vacuum was removed and atmospheric pressure was used to drive the water in the pores. The water level was noted again.

(iii) The change in the level (difference between final and initial, $\sim 1 \mathrm{ml}$ ) represents the volume of metal in the cathode strip. The total volume of the strip is calculated by geometrical dimensions. The difference between total and metal volumes is the void volume. The ratio of the void volume and total volume is the porosity of the porous cathode.

(iv) Steps i-iii were repeated five times for each cathode and an average value of porosity is reported.

Batch experiments were performed with two porous cathodes and a planar nickel cathode. All tests were conducted at a constant cell current of $25 \mathrm{~A}$ for $4 \mathrm{hrs}$. Two catholyte feeds were used for the runs and their compositions are shown in Table 1. Tests were carried out at $\sim 35^{\circ} \mathrm{C}$ and $31^{\circ} \mathrm{C}$ (see Table 3 ). The remaining constant operating conditions are shown in Table 2.

The off gas flowrate was measured using a calibrated gas bubble meter and the gas composition is analyzed using a Hewlett-Packard 5890 gas chromatograph (GC). Samples of the catholyte and anolyte were drawn from the recirculation tanks. The nitrate and nitrite concentrations in the samples were measured using ion chromatography. The hydroxide $\left(\mathrm{OH}^{-}\right)$concentration was obtained by titration with glacial acetic acid. The ammonia concentration in the catholyte was obtained using the Kjeldahl method. The chloride and bromide concentrations, obtained by ion chromatography, were used to 
determine the catholyte volumes at different times. This was done by assuming that the chloride/bromide species do not undergo any reaction and are not transported across the cation selective membrane. Therefore, the moles of chloride and bromide in the catholyte should will remain equal to the initial moles at all times. The concentrations of chloride and bromide will change due to dilution as a result of water transport across the membrane.

The partial current fractions of the five cathodic reactions were determined using the experimental data. Assuming the solubility of $\mathrm{N}_{2}, \mathrm{H}_{2}, \mathrm{~N}_{2} \mathrm{O}$ in the catholyte at these temperatures is negligible, the partial currents for the reactions producing these species were calculated by using Faraday's law. The partial current of reaction[j], $I_{j}$, was calculated from the molar flowrate $\left(\mathbf{F}_{\mathbf{j}}\right)$ of the gas product of that reaction by the following equation:

$$
I_{j}=\frac{n_{j} \mathrm{~F}}{s_{j}} \mathbf{F}
$$

where

$$
\mathbf{F}_{j}=\frac{G v_{j} P}{R T} \quad \text { (assuming ideal gas law is valid) }
$$

The partial current of the ammonia $\left(\mathrm{NH}_{3}\right)$ production reaction was calculated as:

$$
I_{j}=\left(\frac{n_{j} \mathrm{~F}}{s_{j}}\right) \frac{d\left[m_{j}\right]}{d t}+\frac{n_{i} \mathrm{~F}}{s_{i}} \mathbf{F}_{j}
$$

The first term of the above equation is the ammonia current calculated from the moles of ammonia dissolved in the catholyte. The second term is the contribution to current by ammonia released into the gas phase. To calculate the first term of equation (29), the gradient of dissolved moles $\left(\mathrm{m}_{\mathrm{j}}\right)$ was found by plotting the moles of dissolved ammonia versus time and fitting the data to a polynomial. Second order polynomials were found sufficient to fit the data obtained in all the tests: The polynomial equation was then differentiated with respect to time to get the molar gradient $\left(\frac{d\left[m_{j}\right]}{d t}\right)$. The nitrate to nitrite reaction current was obtained using a procedure similar to the one used to obtain the first term of the ammonia current. The partial current fractions of the reactions were obtained by taking the ratio of the partial currents $\left(\mathrm{I}_{\mathrm{j}}\right.$ 's $)$ of the reactions to the cell current $\left(\mathrm{I}_{\text {cell }}\right)$.

Closing the current balance in the first 1.5 hours of the runs proved difficult for almost all the runs having nitrate as feed and some having nitrite as feed. Therefore, most of the data reported is between 1.5 to 4.0 hours. A possible explanation for this discrepancy may be due to an inability to account for all the ammonia produced. A complex ammonia compound may be formed during the initial one hour which is not being detected. Efforts are being made to reduce experimental errors by increasing the sensitivity of the detection methods used. In the results presented below, plots of partial current 
fractions rather than currents are shown owing to the difficulty in getting the sum of the individual reaction currents equal to the value of the cell current passed. This should not introduce a significant error in analysis since the ammonia reaction is dominant throughout all the runs and requires close to $80 \%$ of the cell current at the operating conditions used.

\section{Results and discussion}

The results presented in this report were obtained from both experiments and model simulations. The experimental results will be presented first followed by comparisons between the experimental and model results. Catholyte feeds (feeds 1 and 2 in Table 1) are $0.6 \mathrm{M} \mathrm{NaNO}_{2}$ and $1.9 \mathrm{M} \mathrm{NaNO}_{3}$. The experiments performed using these two feeds will be referred to as nitrite and nitrate runs, respectively.

\section{Nitrite feed}

Figure 4 shows the plots of the partial current fractions obtained using porous nickel foam and TySAR ${ }^{\mathrm{TM}} \mathrm{SB}$ as cathodes at temperatures of 32 and $31^{\circ} \mathrm{C}$, respectively. The results show that ammonia production is the dominant cathodic reaction and accounts for over $80 \%$ of the cell current for both the electrodes. Nitrogen is the second major product. More nitrogen is formed with the nickel foam cathode than the TySAR ${ }^{\mathrm{TM}} \mathrm{SB}$ cathode. With the TySAR ${ }^{\mathrm{TM}} \mathrm{SB}$ cathode, nitrogen is produced only during the initial portion of the run. With nickel foam, nitrogen accounts for less than $10 \%$ of the current followed by hydrogen which accounts for about $1 \%$ of the current, most of which is produced during the later portion of the run. Though not clear from the Figure 4, the nitrous oxide production for TySAR ${ }^{\mathrm{TM}} \mathrm{SB}$ is two orders of magnitude greater than that obtained in the nickel foam tests. This suggest a higher value for the nitrous oxide kinetic parameter on TySAR ${ }^{\mathrm{TM}} \mathrm{SB}$ than nickel. However, the current fraction of the nitrous oxide reaction is still negligible in both the electrodes.

Figure 5 compares the partial current fractions obtained for nickel foam cathodes at temperatures of 32 and $37^{\circ} \mathrm{C}$. The results show that while ammonia production stays dominant at both the temperatures, nitrogen evolution becomes significant at the higher temperature. This may be due to a higher temperature sensitivity of the kinetics of the nitrogen production reaction. The production of hydrogen is also lower at the higher temperature, though the magnitudes at both the temperatures are insignificant. The nitrous oxide reaction is negligible at both the temperatures. Additional runs will be performed in future to confirm these observations.

Figure 6 compares the current fractions for porous nickel foam and planar nickel foil cathodes at temperatures of 37 and $36{ }^{\circ} \mathrm{C}$, respectively. The current distribution is similar to that shown in Figures 4 and 5. Note, the presence of higher hydrogen current $(\sim 5 \%)$ at the planar cathode during the later stages of the run. 
The moles of nitrate and nitrite destroyed with time is shown in Figure 7 for all the cathodes and temperatures used. After 4 hours, the maximum and minimum number of moles destroyed are with the nickel foam and nickel foil cathodes, respectively. This result suggests that nickel foam at the lower temperature will be the most efficient porous cathode among the electrodes. This deduction is supported by the plots of the cathodic overpotential versus time shown in Figure 8 . Nickel foam at $32{ }^{\circ} \mathrm{C}$ requires the lowest overpotential followed by the same cathode at $37^{\circ} \mathrm{C}$. TySAR ${ }^{\mathrm{TM}} \mathrm{SB}$ and nickel foil need at least $0.2 \mathrm{~V}$ more overpotential than the nickel foam to provide the same current. These results suggest that porous nickel foam at $32{ }^{\circ} \mathrm{C}$ consumes less power in the cathode section and destroys more moles of nitrate and nitrite per unit time. More tests over a wider range of temperature are needed to confirm the benefits of operating the cell at low temperatures.

\section{Nitrate feed}

The results obtained using nitrate as catholyte feed are presented in Figure 9-13. Figure 9 shows the partial current fractions obtained using porous nickel foam at $31{ }^{\circ} \mathrm{C}$. Ammonia is the dominant reaction and consumes about $65 \%$ of the cell current followed by the nitrate to nitrite reduction reaction which consumes about $30 \%$ of the current. The ammonia current increases during the run whereas the nitrite production current decreases. Hydrogen evolution consumes about $5 \%$ of current while nitrogen and nitrous oxide production are negligible. Figure 10 shows the partial current fractions obtained on using TySAR ${ }^{\mathrm{TM}} \mathrm{SB}$ at $30^{\circ} \mathrm{C}$ as the cathode. The results for this cathode material are similar to that obtained for the nickel foam except that nitrogen evolution is decreased. Also, the ammonia current fraction shows a decreasing trend and the nitrite current an increasing trend with time. Figure 11 shows the results for planar nickel foil cathode at 29 ${ }^{\circ} \mathrm{C}$. The trends for ammonia and nitrite production are similar to those obtained for the nickel foam. However, the nitrogen current is significant in this test as opposed to the nickel foam test. The nitrous oxide production is negligible with all the three electrodes for the nitrate feed.

The moles of nitrate and nitrite destroyed with time is shown in Figure 12. A plot for TySAR ${ }^{\mathrm{TM}} \mathrm{SB}$ is not shown due to incorrect values obtained from experimental errors. The errors occur as the moles of nitrite in catholyte were found to monotonically increase though the nitrate moles decrease with time. This results in a higher value for the sum of the moles of nitrate and nitrite than the initial value for some time intervals. However, current fractions could be calculated from this data because all the variables used in the calculations (i.e., equations 27-29) showed the expected trends. The trends were decreasing moles of nitrate, and ammonia and consistent values for the nitrogen, hydrogen and nitrous oxide gas flowrates.

Figure 12 shows that both nickel foam and foil yield the same amount of destruction over the time period plotted. Therefore, both the electrodes seem equally 
feasible for the nitrate system at this point. However, the plots of the cathodic overpotential required (see Figure 13) show that the use of the nickel foam cathode is more favorable. The nickel foam exhibited the lowest overpotential followed by the nickel foil at about $0.2 \mathrm{~V}$ more overpotential. TySAR ${ }^{\mathrm{TM}} \mathrm{SB}$ needs the highest overpotential $(\sim 0.4$ $V$ more than nickel foam) and, therefore, may not be suitable due to power considerations.

The results for both the nitrate and nitrite tests suggest that porous nickel foam cathode at a lower temperature would be the most suitable among nickel foam, nickel foil and porous TySAR ${ }^{\mathrm{TM}} \mathrm{SB}$ cathodes. The experimental results for nickel foam at lower temperature for both the nitrate and nitrite system were used to extract the kinetic parameters using the porous cathode model. This was done using the current fractions obtained for different catholye concentrations. Sensitivity analysis by Wingard ${ }^{20}$ showed that the partial current fractions were more sensitive to the exchange-current densities than the transfer coefficients. Therefore, the exchange-current densities were varied while the transfer coefficient were held constant, to obtain model predictions similar to the experimentally obtained partial current fractions. Unfortunately, one set of values of the kinetic parameters $\left(i_{0}\right)$ could not be found to predict the results for both the systems. However, two sets, differing in the value of the hydrogen exchange-current density could be found to match the experimental results. These values are shown in Table 4 . The kinetic parameters for the hydrogen reaction are those deduced for nitrite system and the nitrate system (in parentheses), respectively. The other model parameters such as electrode thickness, porosity and the diffusivities of all the species present, are also shown in Table 4.

\section{Comparison of Model and Experimental Results}

The dynamic model simulations are done using the two sets of kinetic parameters for their respective systems and the results are compared to the experimental results. Also, some steady-state model simulation results are shown and discussed to illustrate the current and gas porosity profiles in the porous cathode bed.

Figure 14 shows the comparison of the model and experimental results for the nitrite catholyte feed. The model predicts linear profiles with essentially constant values for the partial current fractions which agree well with the experimental results up to 3.5 hrs of operation. Model predictions after 3.5 hrs could not be obtained due to computational underflow errors caused due to residual nitrate depletion. Modifications in the model are being made to eliminate this drawback.

Figure 15 shows the reaction current profiles in the porous cathode bed for a steady-state simulation at initial feed conditions. The profiles show that the ammonia production reaction is dominant throughout the bed. Also the entire thickness of the porous cathode is used for reactions, which suggests that the value of thickness used is appropriate for this system at the current density used. Nitrogen and hydrogen evolution are next in magnitude, but still negligible compared to the ammonia current fraction. Both 
show an increasing trend as the surface closest to the anode is approached (i.e., bed depth approaching zero), because the overpotential is highest at this surface.

Figure 16 shows the comparison of the normalized moles of nitrate and nitrite in the system predicted by the model and experiment. The moles are normalized with respect to the initial moles. The predictions show a good agreement in the region of comparison. The model shows a change of slope later in the run which is believed to be due to the depletion of the reactants.

Figure 17 shows the comparison of the cathodic overpotential predicted by the model and the experimental results. The ohmic potential drop in the catholyte section is calculated in the model by using the value of resistivity found by Wingard. ${ }^{20}$ The model and experiment values compare within $0.1 \mathrm{~V}$. Error analysis of the experimental data and accounting for additional ohmic drops due to gas bubbles clogging the cathode surface are planned in future work. This will determine the validity of the model overpotential predictions to experimental data.

Comparison of the partial current fractions and moles of nitrate and nitrite destroyed obtained from the model, and experimentally, provides confidence in the relative magnitudes of the kinetic parameters used. A good agreement of the overpotential values would substantiate the absolute values of the parameters. Since confidence in the overpotential values is still uncertain at present, absolute magnitudes of the kinetic parameters may not be equal to those extracted.

Figures 18-21 show similar comparisons for the nitrate system. The kinetic parameters used are shown in Table 4. Owing to lack of consistent data, the current fractions obtained from experiments can be compared to the model predictions in only the 1.5-3.5 hr period (see Figure 18). The model shows a fair agreement with the experiment data though the confidence level is low because the experimental results show trends for ammonia and for nitrate to nitrite reduction current fractions which disagree with the model. The difference in the trends may be due to errors in analysis of experimental data for calculation of the ammonia and nitrate current fractions. It may also be due to the kinetic parameters used in the model. However, the nitrogen, hydrogen and nitrous oxide current fractions, which are small in value, fit well to the model.

Figure 19 shows the reaction current profiles in the porous cathode bed for a steady-state simulation at feed conditions. The profiles are similar to that obtained for the nitrite system. Ammonia production reaction is dominant throughout the bed followed by the nitrate-to-nitrite reduction reaction. The hydrogen evolution reaction is next in magnitude but still negligible compared to ammonia and nitrate-to-nitrite current fractions.

Figure 20 shows the comparisons for the normalized moles of nitrate and nitrite present. The agreement was found to be within $5 \%$. The normalized mole values remain at a higher level in the case of the nitrate feed compared to nitrite feed (see Figure 16). This effect is because a higher concentration is used in the case of nitrate feed compared to 
nitrite feed. Therefore, more moles of the reactant are present and since the destruction current is same, the molar depletion is slower.

Figure 21 shows the comparison of the model and experimental results for cathodic overpotential for the nitrate system. The results show excellent agreement and support the validity of the kinetic parameters used for this system.

To study the effect of the catholyte feed on the gas generation reactions, the maximum gas void fraction in the porous nickel bed (i.e., at the surface facing anode) is plotted for the two systems as a function of time. The results are shown in Figure 22 . The void fraction, though being less than $1 \%$ of the bed porosity, is more for the nitrite feed than the nitrate feed. This is due to more nitrogen gas evolution in the nitrite feed. The plots show an increasing trend with time due to the increase in the gas generation reaction (nitrogen and hydrogen) in the later part of the simulation due to depletion of nitrate and nitrite. The value, however, is still low because the ammonia reaction remains the dominant reaction, and since it is soluble in catholyte as soon as it is produced, it does not affect the gas void fraction.

Figure 23 shows the profiles of the gas void fraction with bed depth for the nitrate and nitrite feeds. The void fraction values for nitrite are always greater than that for nitrate due to reasons explained earlier. Also, the values follow an increasing trend toward the side facing the anode. At this surface the higher overpotential favors the nitrogen and hydrogen reactions more than at bed depths farther from the anode. At farther bed depths, the overpotential is lower due to ohmic potential drops.

\section{Conclusions and Recommendations}

Nickel foam has been found to be the most suitable cathode material among the three materials evaluated: (i) nickel foam, (ii) nickel plate and (iii) $\operatorname{TySAR}^{\mathrm{TM}} \mathrm{SB}$. Operation of the nickel foam cathode at lower temperatures appears to improve the electrical efficiency for the reduction of nitrate and nitrite. This conclusion is based on moles of nitrate and nitrite destroyed and the overpotential needed for the constant current $\left(0.25 \mathrm{~A} / \mathrm{cm}^{2}\right)$ batch experiments.

Ammonia is the main product for all three cathodes at the temperatures and feeds used in the experiments. Almost all of the ammonia produced dissolves due to its high solubility in alkaline solution. After ammonia, nitrite and nitrogen were the next most abundant products in nitrate and nitrite catholyte feeds, respectively. Hydrogen current fraction was found to be less than $1 \%$ and that for nitrous oxide was negligible for all the experiments.

Kinetic parameters could be extracted using the model to predict the experimental results. However getting the same set of kinetic parameters to predict the results for both 
the nitrite and nitrate runs proved difficult. Efforts are continuing to extract the best fit values for these parameters using more experimental data sets. Work is also being done to increase the sensitivity of the experimental measurements.

Experimental studies will be performed to analyze the effect of temperature on the product distribution, destruction efficiencies and the overpotentials. These results will be used along with model simulations to get an optimum current that has high destruction rates as well as high current efficiencies. Experiments will be then done to verify the model predictions and address scale-up issues. 


\begin{tabular}{|c|c|c|c|}
\hline \multicolumn{2}{|c|}{ Feed\# 1 } & \multicolumn{2}{c|}{ Feed\# 2 } \\
\hline Component & $\begin{array}{c}\text { Concentration } \\
(\mathbf{M})\end{array}$ & Component & $\begin{array}{c}\text { Concentration } \\
(\mathbf{M})\end{array}$ \\
\hline $\mathrm{NaNO}_{3}$ & 1.95 & $\mathrm{NaNO}_{2}$ & 0.6 \\
\hline $\mathrm{NaOH}$ & 1.33 & $\mathrm{NaOH}$ & 1.33 \\
\hline $\mathrm{NaCl}$ & 0.281 & $\mathrm{NaCl}$ & 0.281 \\
\hline $\mathrm{NaBr}$ & 0.125 & $\mathrm{NaBr}$ & 0.125 \\
\hline
\end{tabular}

Table 1: Catholyte feed concentrations

\begin{tabular}{|c|c|c|c|}
\hline $\begin{array}{c}\text { Current } \\
\text { density } \\
\left(\mathbf{A} / \mathrm{cm}^{2}\right)\end{array}$ & $\begin{array}{c}\text { Initial Catholyte } \\
\text { volume }\left(\mathrm{cm}^{3}\right)\end{array}$ & $\begin{array}{c}\text { Catholyte flowrate } \\
\left(\mathrm{cm}^{3} / \mathbf{s}\right)\end{array}$ & $\begin{array}{c}\text { Anolyte flowrate } \\
\left(\mathrm{cm}^{3} / \mathbf{s}\right)\end{array}$ \\
\hline 0.25 & 3000 & 31.5 & 31.5 \\
\hline
\end{tabular}

Table 2: Experimental conditions common for all the MP cell runs.

\begin{tabular}{|l|c|c|}
\hline \multicolumn{1}{|c|}{ Electrode } & Feed\# & Temperature $\left({ }^{\circ} \mathbf{C}\right)$ \\
\hline Porous nickel foam & 1 & 31 \\
& 2 & 32,37 \\
\hline Porous TySAR & & \\
& 1 & 31 \\
& 2 & 30 \\
\hline Planar nickel foil & 1 & 29 \\
& 2 & 36 \\
\hline
\end{tabular}

Table 3: Summary of the conditions used the experimental runs. These are in addition to those listed in Table 2 which are common to all the runs reported. 


\begin{tabular}{|c|c|c|}
\hline Reaction \# & $\begin{array}{l}\text { Exchange-current Densities } \\
\left(\mathbf{A} / \mathrm{cm}^{2}\right)\end{array}$ & $\begin{array}{c}\text { Transfer coefficient } \\
(\mathbf{n} \alpha)\end{array}$ \\
\hline 1 & $1.0 \times 10^{-10}$ & 0.42 \\
\hline 2 & $2.0 \times 10^{-09}$ & 0.50 \\
\hline 3 & $5.0 \times 10^{-15}$ & 0.50 \\
\hline 4 & $1.0 \times 10^{-15}$ & 0.50 \\
\hline 5 & $1.0 \times 10^{-05}\left(1.0 \times 10^{-06}\right)$ & 0.80 \\
\hline 6 & $2 \times 10^{-04}$ & 0.17 \\
\hline 7 & $1.0 \times 10^{-10}$ & 0.42 \\
\hline Species & $\begin{array}{c}\text { Diffusion Coefficients } \\
\left(\mathrm{cm}^{2} / \mathrm{s}\right)\end{array}$ & \\
\hline $\mathrm{Na}^{+}$ & $1.334 \times 10^{-05}$ & \\
\hline $\mathrm{OH}$ & $5.26 \times 10^{-05}$ & \\
\hline $\mathrm{NO}_{3}^{-}$ & $1.902 \times 10^{-05}$ & \\
\hline $\mathrm{NO}_{2}^{-}$ & $1.902 \times 10^{-05}$ & \\
\hline $\mathrm{N}_{2}$ & $1.9 \times 10^{-05}$ & \\
\hline $\mathrm{NH}_{3}$ & $2.168 \times 10^{-05}$ & \\
\hline $\mathrm{N}_{2} \mathrm{O}$ & $1.801 \times 10^{-05}$ & \\
\hline $\mathrm{O}_{2}$ & $2.151 \times 10^{-05}$ & \\
\hline & $2.322 \times 10^{-05}$ & \\
\hline \multicolumn{3}{|l|}{ Cathode thickness: } \\
\hline Nickel foam & $0.295 \pm 0.005 \mathrm{~cm}$ & \\
\hline TySAR $^{\mathrm{TM}} \mathrm{SB}$ & $0.356 \pm 0.005 \mathrm{~cm}$ & \\
\hline \multicolumn{3}{|l|}{ Cathode porosity: } \\
\hline Nickel foam & $0.87 \pm 0.05$ & \\
\hline TySAR $^{\mathrm{TM}} \mathrm{SB}$ & $0.85 \pm 0.05$ & \\
\hline Superficial Electrode area & $100.0 \mathrm{~cm}^{2}$ & \\
\hline Anode to cathode distance & $1.25 \mathrm{~cm}$ & \\
\hline Separator thickness & $0.05 \mathrm{~cm}$ & \\
\hline MacMullin number & 5.0 & \\
\hline diffusion layer thickness & $15.5 \times 10^{-3} \mathrm{~cm}$ & \\
\hline
\end{tabular}

Table 4 : Kinetic and Physical parameters for the nitrate/nitrite system. The exchangecurrent densities were extracted using the model and the values in and outside parentheses for reaction\# 5 are for ones obtained for nitrate and nitrite feed, respectively. 


\section{NOTATION}

a : interfacial area per volume of bed, $\mathrm{cm}^{-1}$ (a value of $100 \mathrm{~cm}^{-1}$ used in present study\}

$\mathrm{C}_{\mathrm{i}} \quad$ : $\quad$ Molar concentration of species $i, \mathrm{~mol} / \mathrm{cm}^{3}$

$\mathrm{C}_{\mathrm{i}, \mathrm{b}, \mathrm{a}}$ : Bulk concentration of species $i$ in the anolyte, $\mathrm{mol} / \mathrm{cm}^{3}$

$\mathrm{C}_{\mathrm{i}, \mathrm{b}, \mathrm{c}} \quad$ : $\quad$ Bulk concentration of species $i$ in the catholyte, $\mathrm{mol} / \mathrm{cm}^{3}$

$\mathrm{C}_{\mathrm{i}, \mathrm{ref}, \mathrm{j}}$ : $\quad$ Concentration of species $i$ in reaction $\mathrm{j}$ at reference conditions, $\mathrm{mol} / \mathrm{cm}^{3}$

$\mathrm{C}_{\mathrm{i}, \mathrm{s}, \mathrm{a}}: \quad$ Concentration of species $i$ at the anode surface, $\mathrm{mol} / \mathrm{cm}^{3}$

$\mathrm{C}_{\mathrm{i}, \mathrm{s}, \mathrm{c}} \quad$ : Concentration of species $i$ at the cathode surface, $\mathrm{mol} / \mathrm{cm}^{3}$

$\mathrm{D}_{\mathrm{i}}$ : Diffusion coefficient of species $i, \mathrm{~cm}^{2} / \mathrm{s}$

F : Faraday's constant, $96487 \mathrm{C} / \mathrm{mol}$

f : $\quad \mathrm{F} /(\mathfrak{R T}), \mathrm{C} / \mathrm{J}$

$\mathrm{F}_{\mathrm{j}} \quad$ : $\quad$ Molar flowrate of gas produced by reaction $j, \mathrm{~mol} / \mathrm{s}$

G : Total volumetric flowrate of off gases from catholyte recirculation tank, $\mathrm{cm}^{3} / \mathrm{s}$

i : $\quad$ Solution current, $\mathrm{A} / \mathrm{cm}^{2}$

$\mathrm{i}_{0, \text { refj } \mathrm{j}} \quad$ : exchange-current density of reaction $\mathrm{j}$ at reference conditions, $\mathrm{A} / \mathrm{cm}^{2}$

$i_{j} \quad$ : Partial current density of reaction $j, \mathrm{~A} / \mathrm{cm}^{2}$

$\mathrm{I}_{\text {cell }} \quad$ : Cell current, $\mathrm{A} / \mathrm{cm}^{2}$

$\mathrm{I}_{\mathrm{j}} \quad$ : Partial current of reaction $j$ calculated from experimental data at sample times, A

$i_{t} \quad: \quad$ Total current density, $\mathrm{A} / \mathrm{cm}^{2}$

$j_{j} \quad$ : interfacial reaction current of reaction $j, A / \mathrm{cm}^{2}$

$\mathrm{j}_{\mathrm{t}} \quad$ : Total interfacial current, $\mathrm{A} / \mathrm{cm}^{2}$

$\mathrm{M}_{\mathbf{i}} \quad$ : $\quad$ Species “ $i$ " indicator 
$\mathrm{m}_{\mathrm{j}} \quad$ : $\quad$ Moles of dissolved products from reaction $j, \mathrm{~mol}$

$\mathrm{N}_{\mathrm{i}} \quad$ : $\quad$ Flux of species $i$ in the boundary layer, $\mathrm{mol} / \mathrm{cm}^{2} . \mathrm{s}$

$N_{i, s}: \quad$ Flux of species $i$ through the separator, $\mathrm{mol} / \mathrm{cm}^{2} . \mathrm{s}$

$\mathrm{n}_{\mathrm{j}} \quad$ : Number of electrons taking part in reaction $j$

$\mathrm{N}_{\mathrm{m}} \quad$ : MacMullin number

P : Operating pressure, atm.

$\mathrm{p}_{\mathrm{ij}} \quad$ : $\quad$ Order of reaction $j$ with respect to reactant $i$

Q : Catholyte flowrate, $\mathrm{cm}^{3} / \mathrm{s}$

$\mathrm{q}_{\mathrm{ij}} \quad$ : $\quad$ Order of reaction $j$ with respect to product $i$

$\mathfrak{R} \quad$ : Universal gas constant, $8.314 \mathrm{~J} /(\mathrm{mol} \mathrm{K})$

$\mathrm{s}_{\mathrm{ij}} \quad$ : $\quad$ Stoichiometric coefficient of species $i$ in reaction $j$

T : $\quad$ Catholyte temperature, $\mathrm{K}$

$\mathrm{U}_{\mathrm{j}, \mathrm{ref}} \quad$ : $\quad$ Equilibrium potential of reaction $j$ at reference conditions, $\mathrm{V}$

$\mathrm{U}_{\mathrm{j}}^{\theta}$ : $\quad$ Equilibrium potential of reaction $j$ at standard conditions, $V$

$\mathrm{V}$ : Catholyte volume, $\mathrm{cm}^{3}$

$V_{a} \quad: \quad$ Potential of the metal anode, $V$

$V_{c}:$ Potential at the electrode surface of the cathode, $V$

$v_{j} \quad$ : Volume fraction of gaseous product of reaction $j$ obtained experimentally at sample times from catholyte off gases.

z : distance in the porous cathode from the surface of the bed, $\mathrm{cm}$

$\mathrm{z}_{\mathrm{i}} \quad$ : $\quad$ Charge carried by species $i$

\section{Subscripts}

$\begin{array}{lll}\text { a } & : & \text { Anode region } \\ \text { b } & : & \text { Bulk conditions }\end{array}$




$\begin{array}{lll}\text { c } & : & \text { Cathode region } \\ \text { g } & : & \text { Gas } \\ \text { j } & : & \text { Reaction } \\ \text { i } & : & \text { Species } \\ \text { ref } & : & \text { Reference conditions } \\ \text { s } & : & \text { Conditions at the electrode surface }\end{array}$

\section{Greek}

\begin{tabular}{|c|c|c|}
\hline$\alpha_{\mathrm{a}}$ & : & Anodic transfer coefficient \\
\hline$\alpha_{c}$ & : & Cathodic transfer coefficient \\
\hline$\gamma$ & : & Variable defined by equation (15), $\mathrm{cm}^{-1}$ \\
\hline$\delta$ & : & Diffusion layer thickness, $\mathrm{cm}$ \\
\hline$\delta_{s}$ & : & Separator thickness, $\mathrm{cm}$ \\
\hline$\eta_{\text {ref }}$ & : & Overpotential of reaction $\mathrm{j}$ at reference conditions, $\mathrm{V}$ \\
\hline$\theta$ & $:$ & Total bed porosity \\
\hline$\theta_{\mathrm{g}}$ & : & Porosity due to gas \\
\hline$\kappa_{\mathbf{a}}$ & : & Conductivity of the anolyte, $\Omega^{-1} \mathrm{~cm}^{-1}$ \\
\hline$\kappa_{c}$ & : & Conductivity of the catholyte, $\Omega^{-1} \mathrm{~cm}^{-1}$ \\
\hline$\kappa_{\text {eff }}$ & : & Conductivity of electrolyte having gas bubbles in porous bed, $\Omega^{-1} \mathrm{~cm}^{-1}$ \\
\hline$\kappa_{\mathbf{s}}$ & : & Conductivity of the separator, $\Omega^{-1} \mathrm{~cm}^{-1}$ \\
\hline & : & Solution potential near the cathode, $\mathrm{V}$ \\
\hline
\end{tabular}




\section{References}

1. D. Golub and Y. Oren, J. Appl. Electrochem., 19, 311 (1989).

2. D. Pletcher, I. Whyte, F. C. Walsh and J. P. Millington, J. Appl. Electrochem., 21, 667 (1991).

3. M. E. El-Shakre, M. M. Saleh, B. E. El-Anadouli and B. G. Ateya, J. Electrochem. Soc., 141, 441 (1994).

4. J. N. Bennion and J. Newman, J. Appl. Electrochem., 2, 113 (1972).

5. A. T. Kuhn, J. Appl. Electrochem., 4, 69 (1974).

6. J. A. Trainham and J. Newman, J. Appl. Electrochem., 124, 1528 (1977).

7. M. Saleh, J. Weidner, B. El-Anadouli and B. Ateya, submitted the J. Electrochem Soc., (1995)

8. D. T. Chin and B. Eckert, Plat. Surf. Finish., 10, 38 (1976).

9. D. T. Hobbs and M. Ebra, AIChE Symp. Series No. 254, 83, 149 (1987).

10. D. T. Hobbs, G. D. Genders and D. Hartsough, Abstract 568, p. 910, The Electrochemical Society Extended Abstracts, Vol. 94-1, San Fransico, CA, May 22271994.

11. Hu-lin Li, D. Robertson, J. Chambers and D. T. Hobbs, J. Electrochem. Soc., 135, 1154 (1988).

12. D. T. Hobbs, 'Electrochemical Treatment of Nuclear Waste at Savannah River Site" in Electrochemistry for a Cleaner Environment, J. D. Genders and N. Weinberg, Editors, The Electrosynthesis Company, Amherst, New York (1992).

13. D. Coleman, R. E. White and D. T. Hobbs, J. Eectrochem. Soc., 142, 115 (1995).

14. S. Prasad, J. Weidner and A. Farell, submitted the J. Eectrochem. Soc., (1995).

15. K. Jha and J. Weidner, "Evaluation of Porous Cathode Used for the Electrochemical Reduction of Nitrates and Nitrites in Liquid Wastes", A Milestone Report, Sept. (1994).

16. A. J. Bard and L. R. Faulkner, 'Electrochemical Methods: Fundamentals and Applications", John Wiley \& Sons, New York, NY, 1980. 
17. J. Newman, "Electrochemical Systems", 2nd Ed., Prentice Hall, Englewood Cliffs, NJ, 1991.

18. D. Fan and R. E. White, J. Electrochem. Soc, 138, 2952 (1991).

19. Kreyszig, "Advanced Engineering Mathematics", 5th Ed., Wiley Eastern Limited, 1993.

20. D. Wingard, "An Analysis of the Batch Electrochemical Reduction of $\mathrm{NO}_{3}{ }^{-} / \mathrm{NO}_{2}{ }^{-}$in Low-Level Radioactive Waste", Ph.D thesis (1995), University of South Carolina, Columbia. 


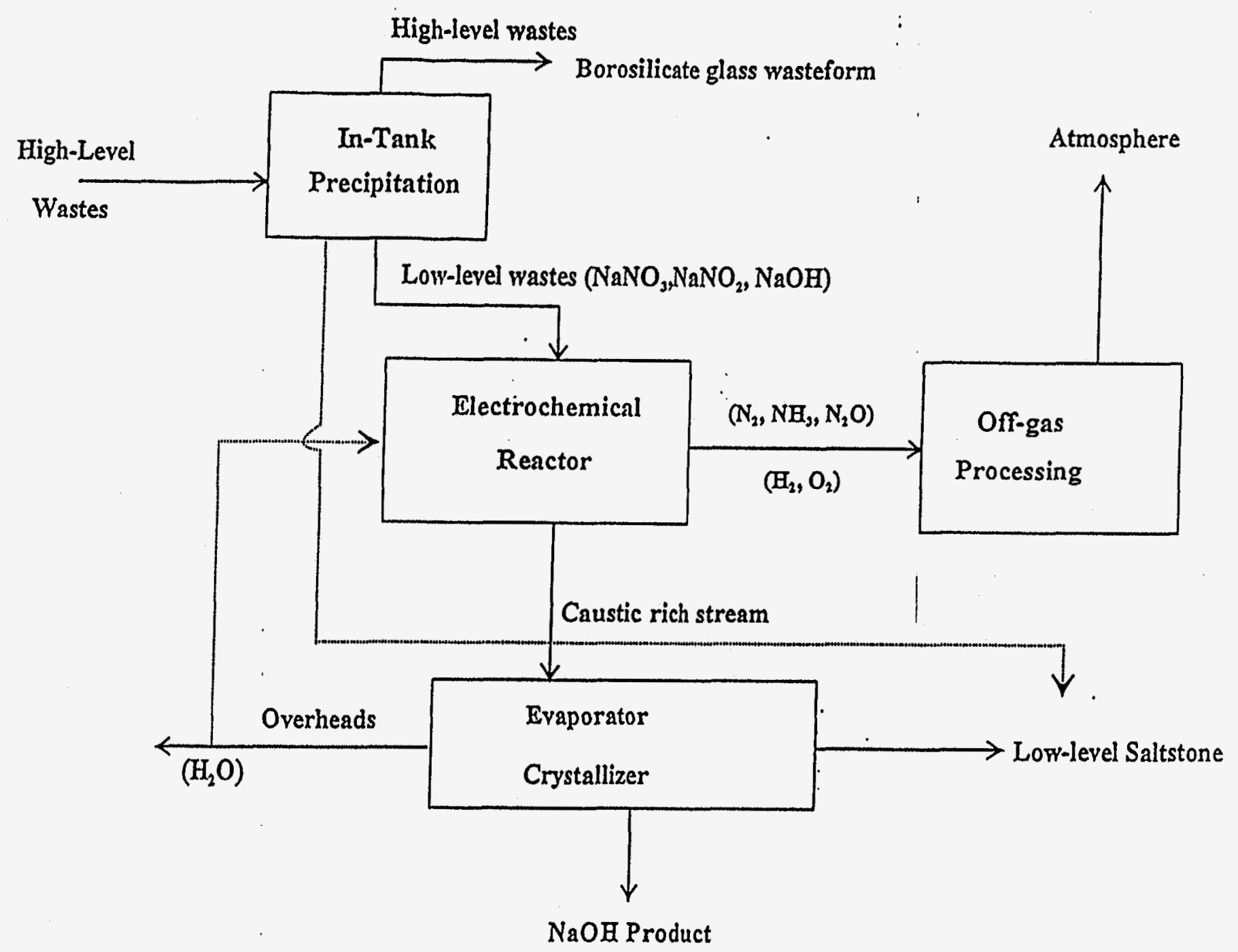

Figure 1: Process Flowsheet of the Electrochemical Treatment of Liquid Radioactive Wastes. 


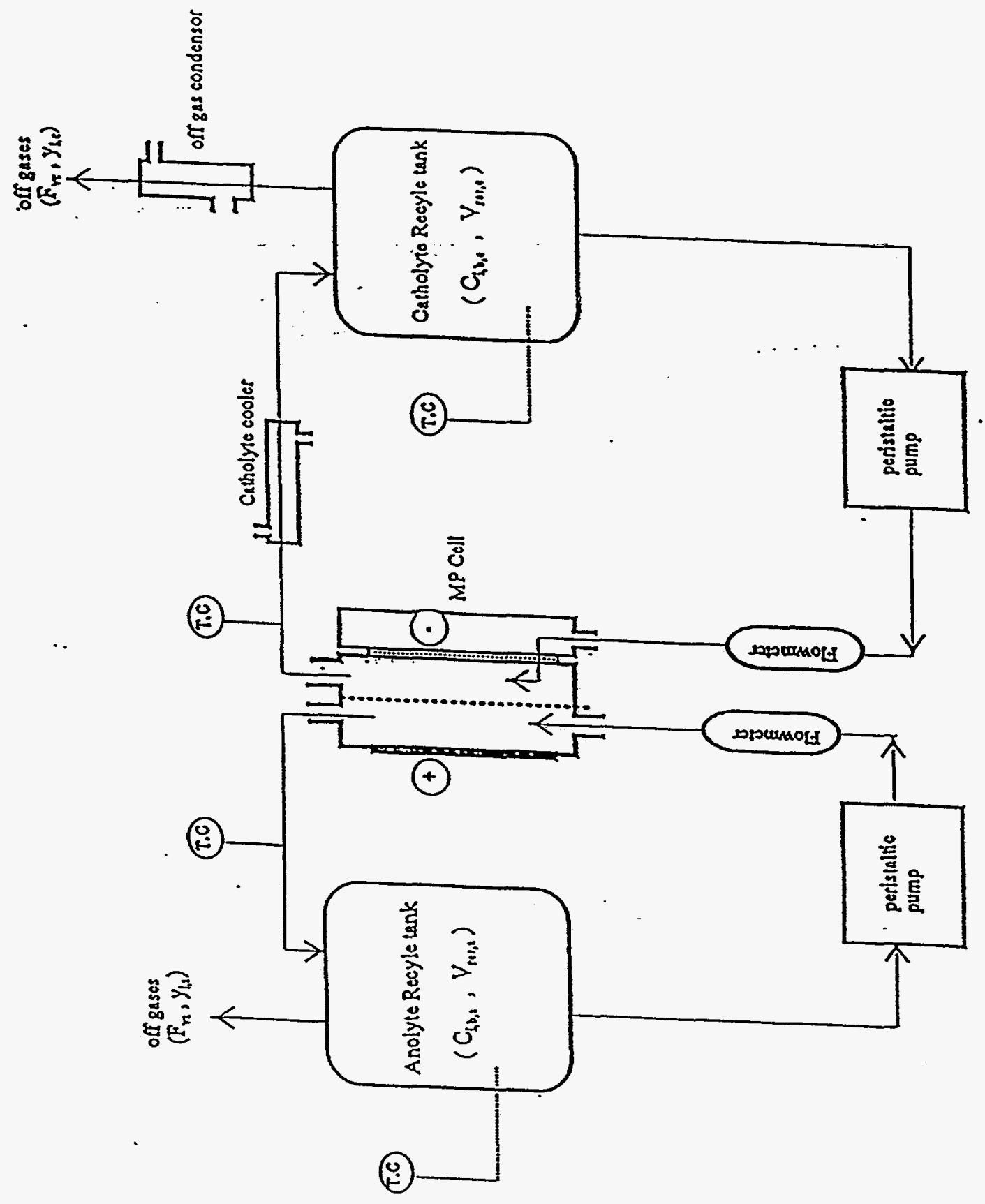




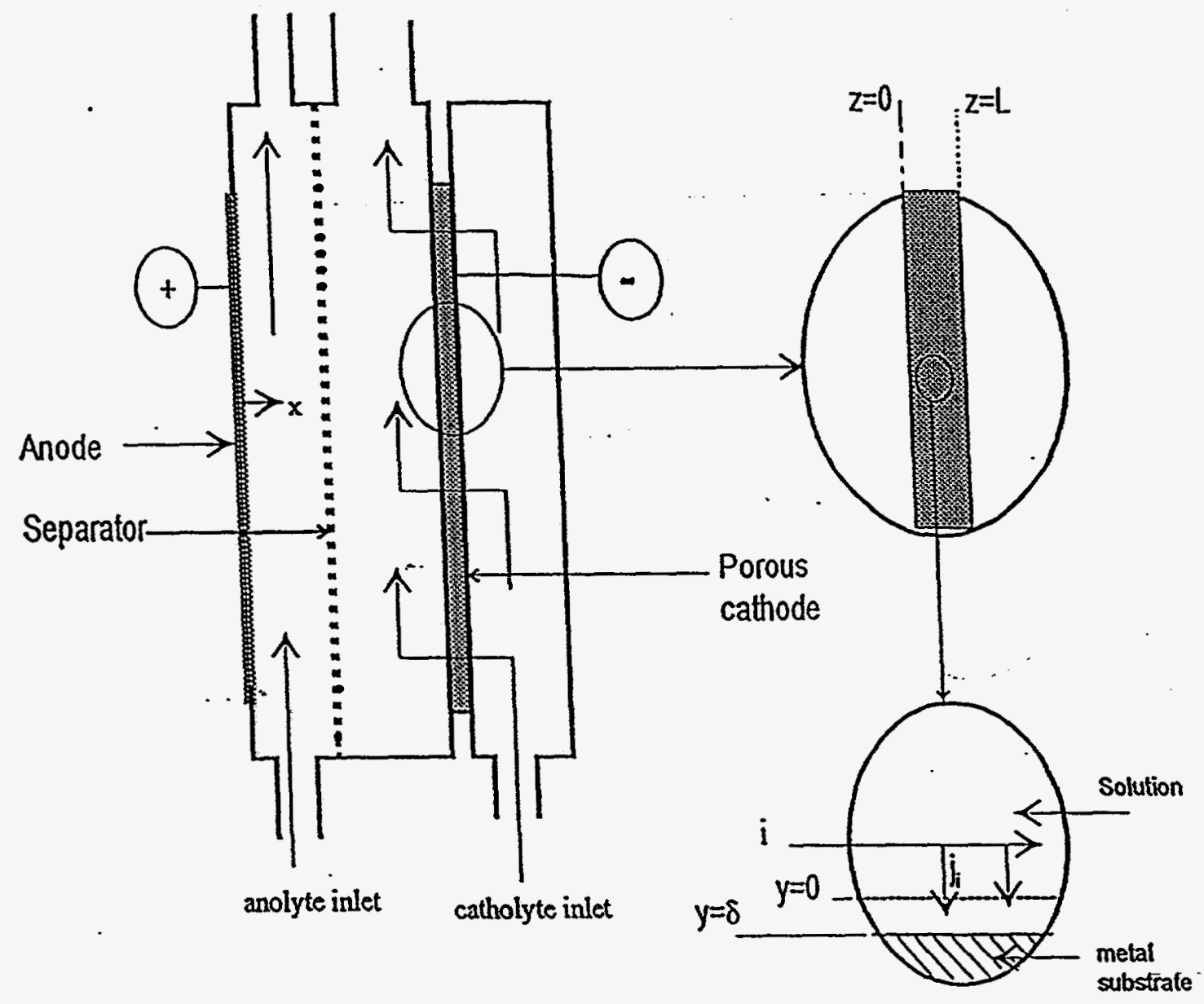

Figure 3: Schematic of the Divided MP Cell with a Porous Cathode. 


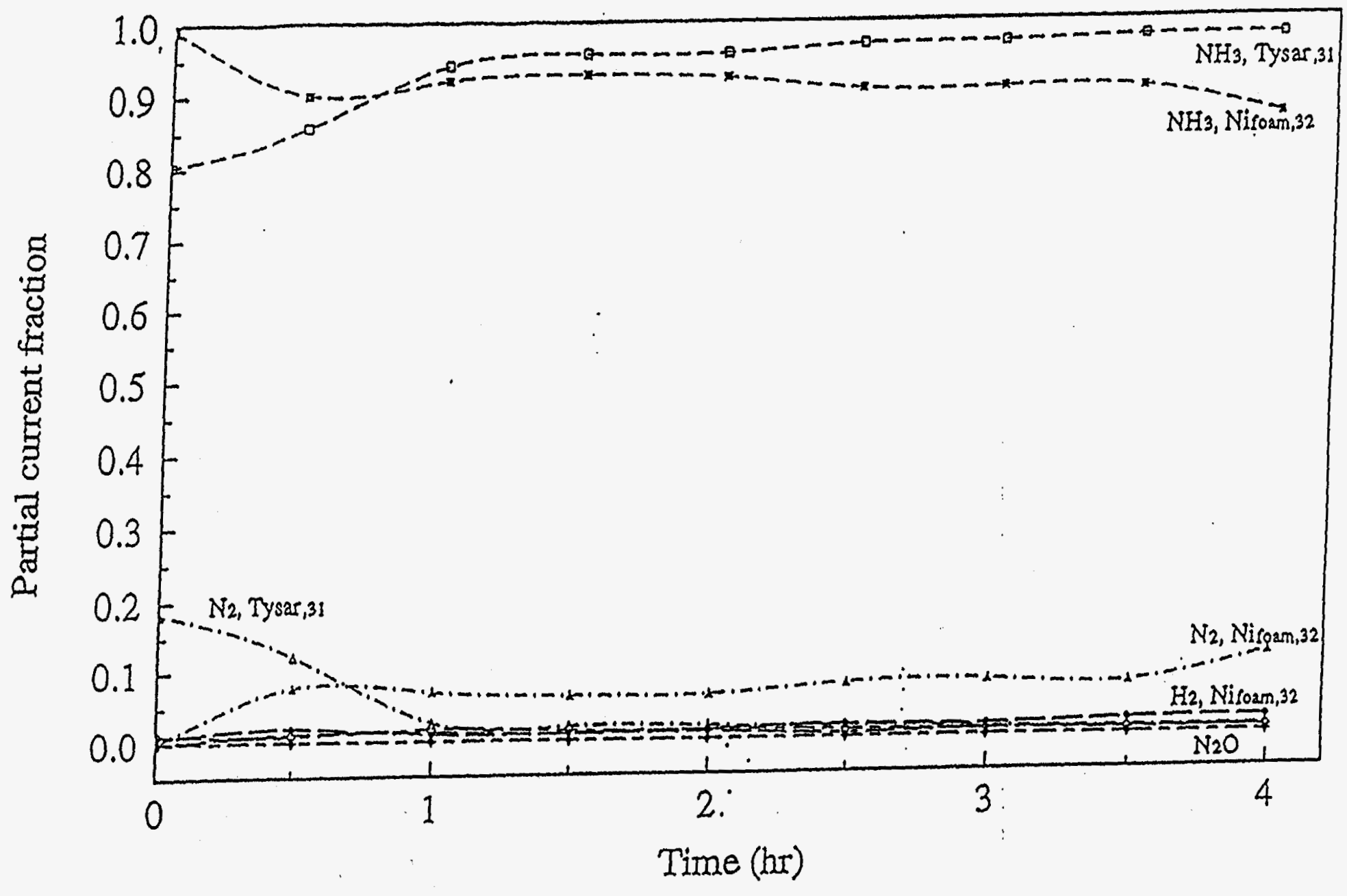

Figure 4: Experimental results for the partial current fractions of the cathodic reactions using: (i) porous nickel foam at $32^{\circ} \mathrm{C}$, aind (ii) porous TySAR ${ }^{\mathrm{IM}} \mathrm{SB}$ at $31^{\circ} \mathrm{C}$ as cathodes. The temperature values are also shown in subcripts with the electrode name on the plots. The results for nickel foam and TySAR ${ }^{T M} S B$ are represented by splines fitted to filled and empty symbols respectively, where the symbols are at the data points obtained. Initial catholyte concentration was $0.6 \mathrm{M} \mathrm{NaNO}_{2}$. 


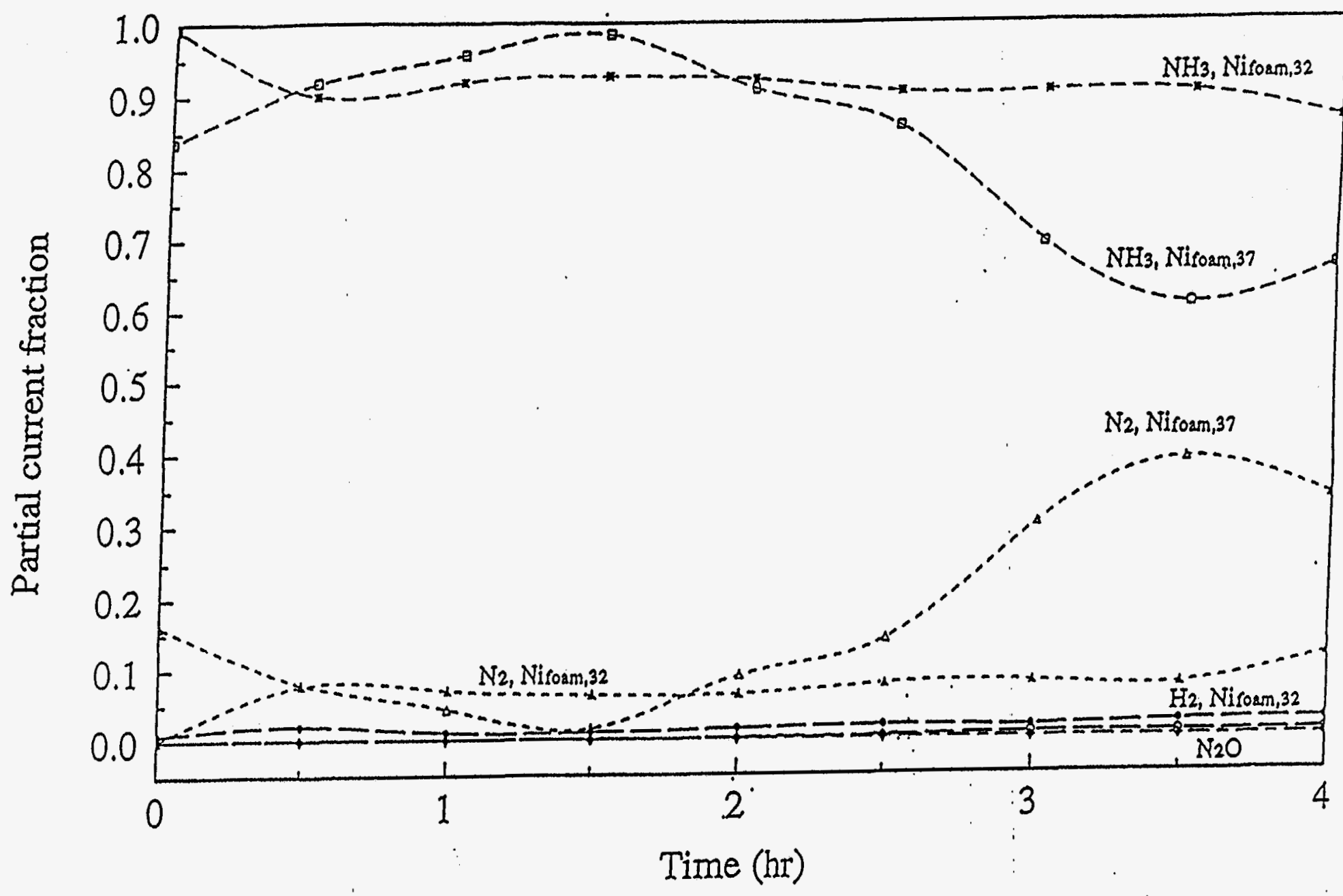

Figure 5: Experimental results for the partial current fractions of the cathodic reactions using: (i) porous nickel foam at $32{ }^{\circ} \mathrm{C}$, and (ii) porous nickel foam at $37{ }^{\circ} \mathrm{C}$ as cathodes. The temperature values are also shown in subcripts with the electrode name on the plots. The results for nickel foam at 32 and $37^{\circ} \mathrm{C}$ are represented by splines fitted to filled and empty symbols respectively, where the symbols are at the data points obtained. Initial catholyte concentration was $0.6 \mathrm{M} \mathrm{NaNO}_{2}$. 


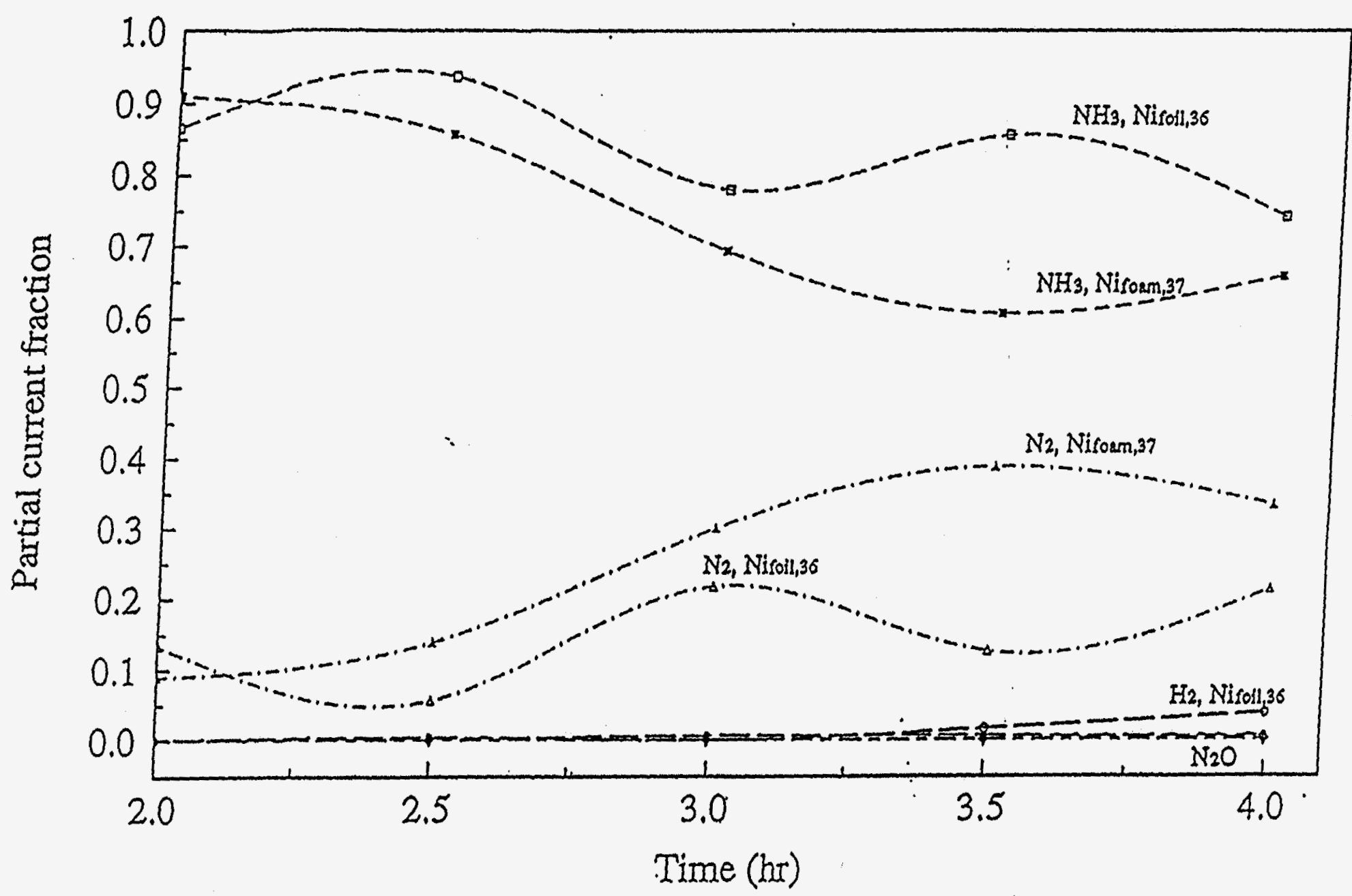

Figure 6: Experimental results for the partial current fractions of the cathodic reactions using: (i) porous nickel foam at $37^{\circ} \mathrm{C}$, and (ii) planar nickel foil at $36^{\circ} \mathrm{C}$ as cathodes. The temperature values are also shown in subcripts with the electrode name on the plots. The results for nickel foam and foil are represented by splines fitted to filled and empty symbols respectively, where the symbols are at the data points obtained. Initial catholyte concentration was $0.6 \mathrm{M} \mathrm{NaNO}_{2}$. 


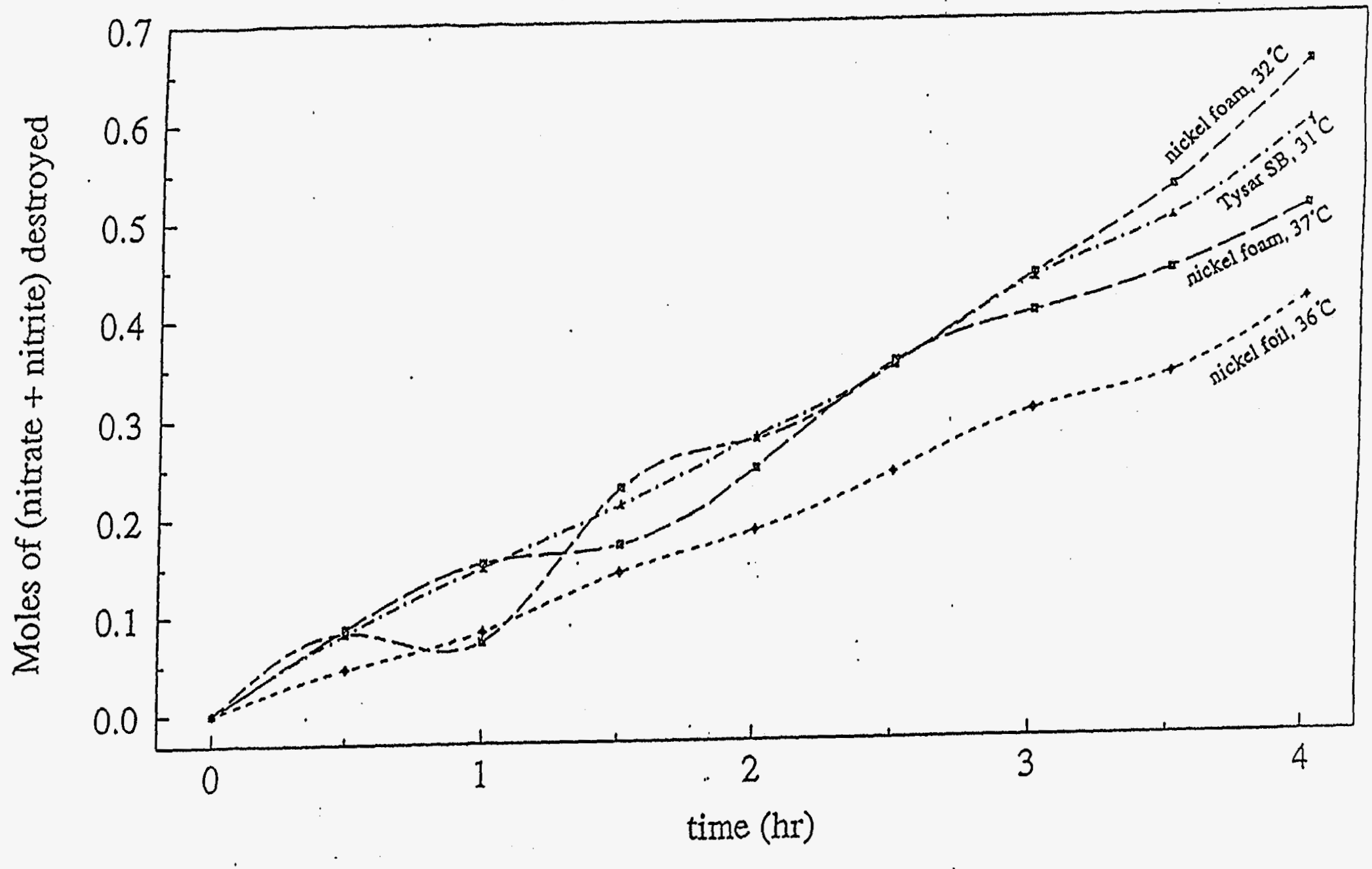

Figure 7: Moles of nitrate and nitrite destroyed for constant current runs using porous nickel foam, porous TySAR ${ }^{T M} \mathrm{SB}$ and planar nickel foil as cathodes. The initial catholyte concentration was $0.6 \mathrm{M} \mathrm{NaNO}$ (traces of nitrate $\sim 0.02 \mathrm{M}$ were also present). The catholyte temperatures are shown on the plots. 


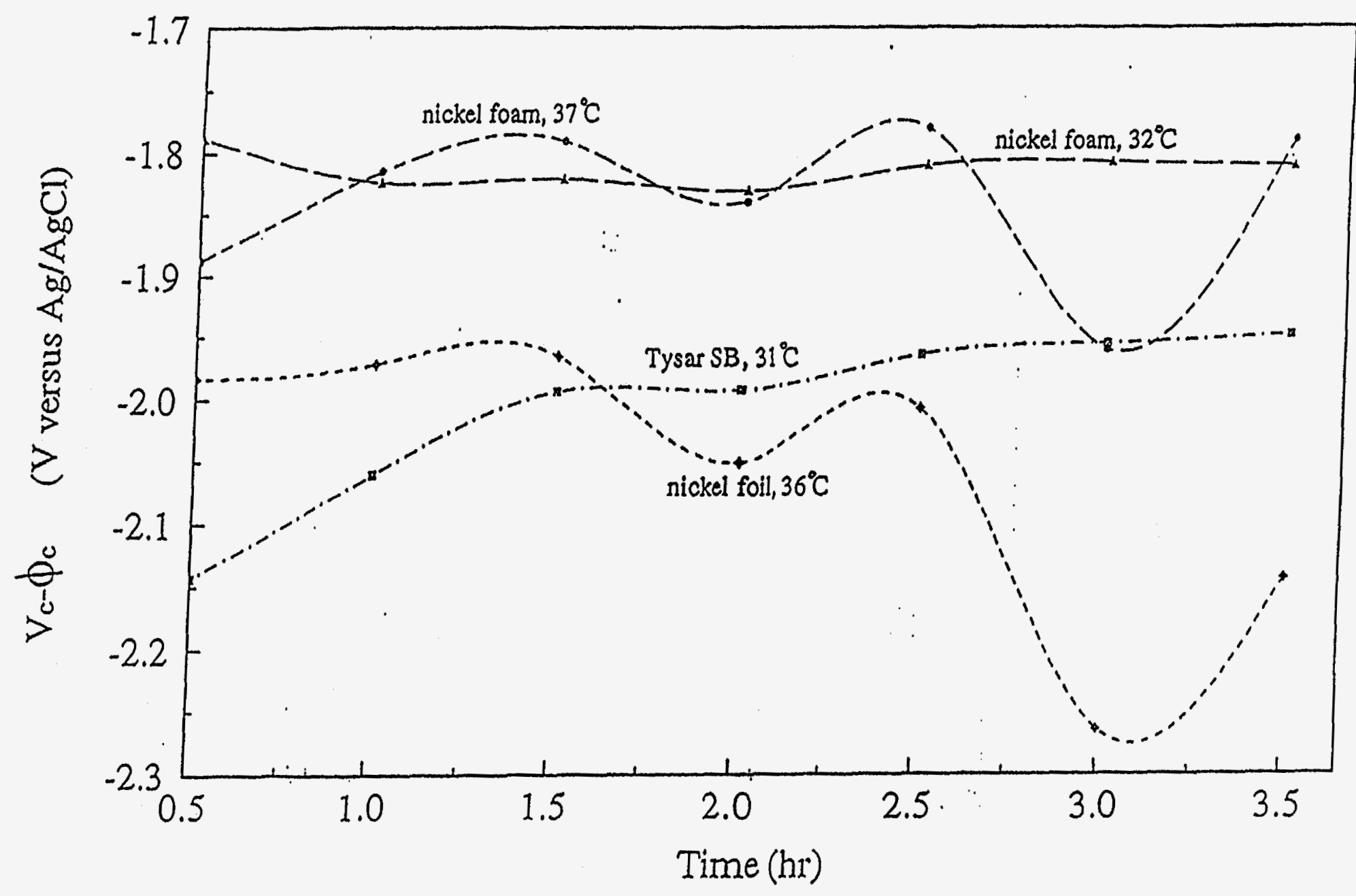

Figure 8: Cathodic overpotential needed for constant current runs using porous nickel foam, porous TySAR ${ }^{T M} S B$ and planar nickel foil as cathodes. The initial catholyte concentration was $0.6 \mathrm{M} \mathrm{NaNO}_{2}$. The catholyte temperatures are shown on the plots. 


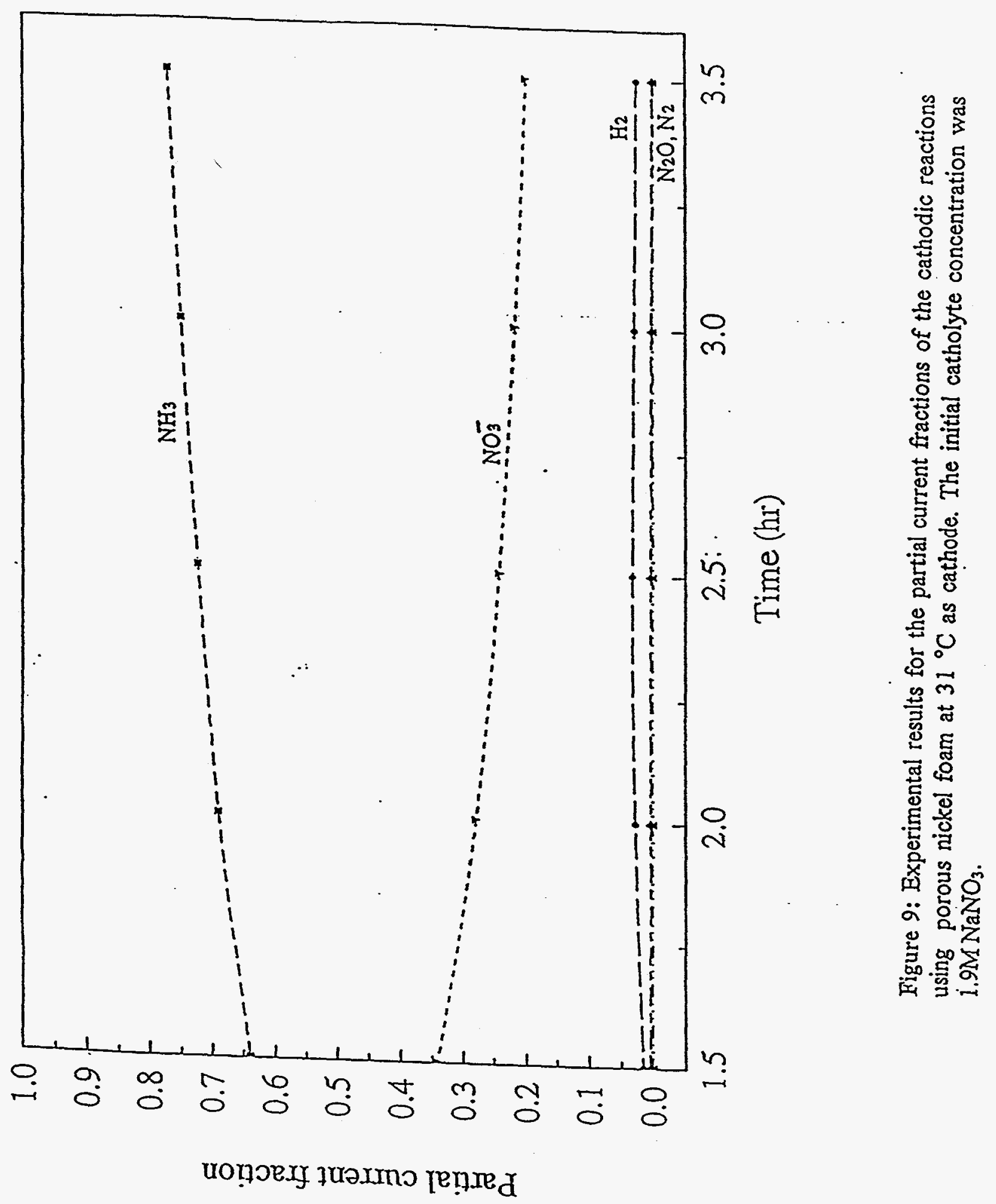




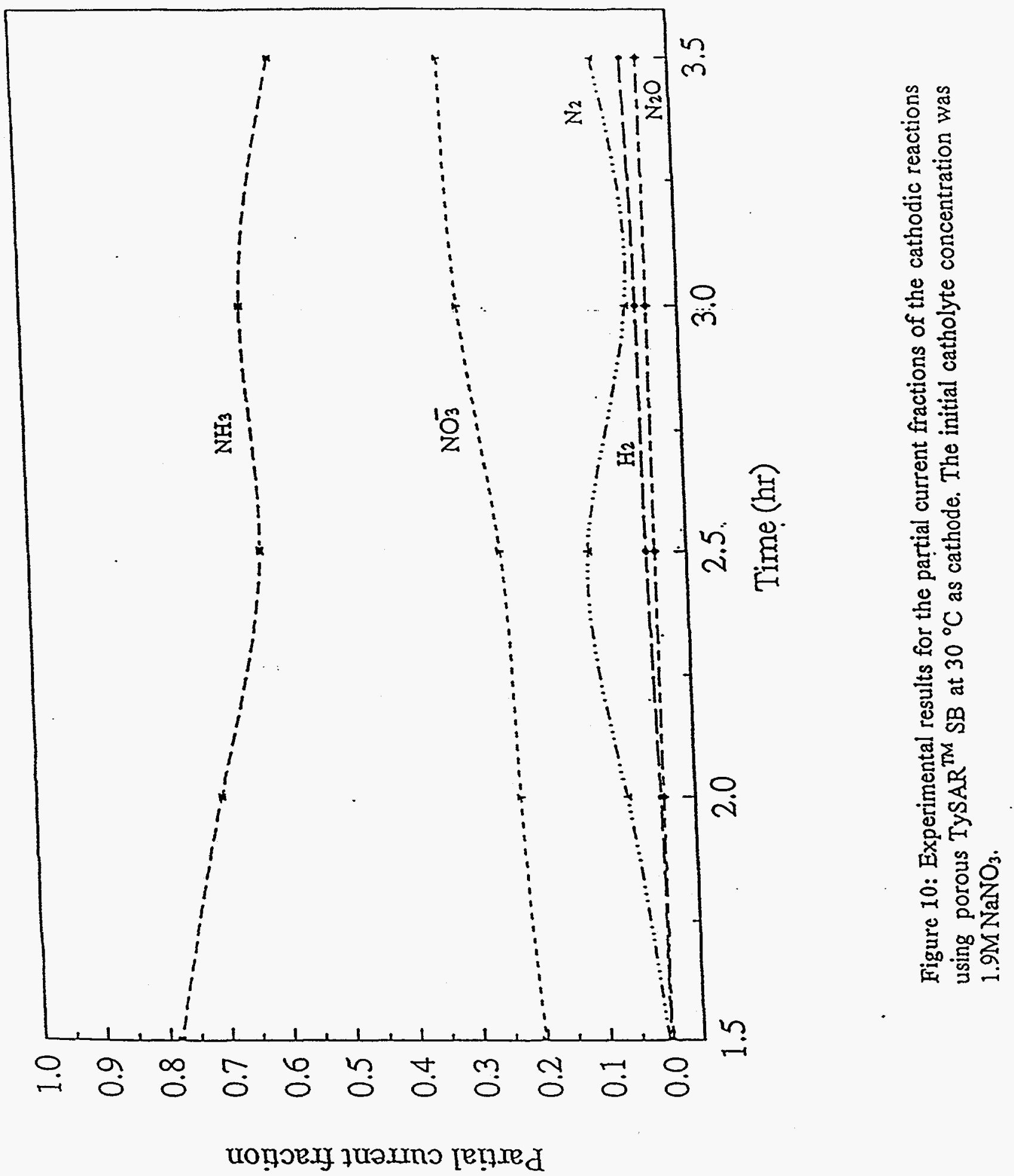




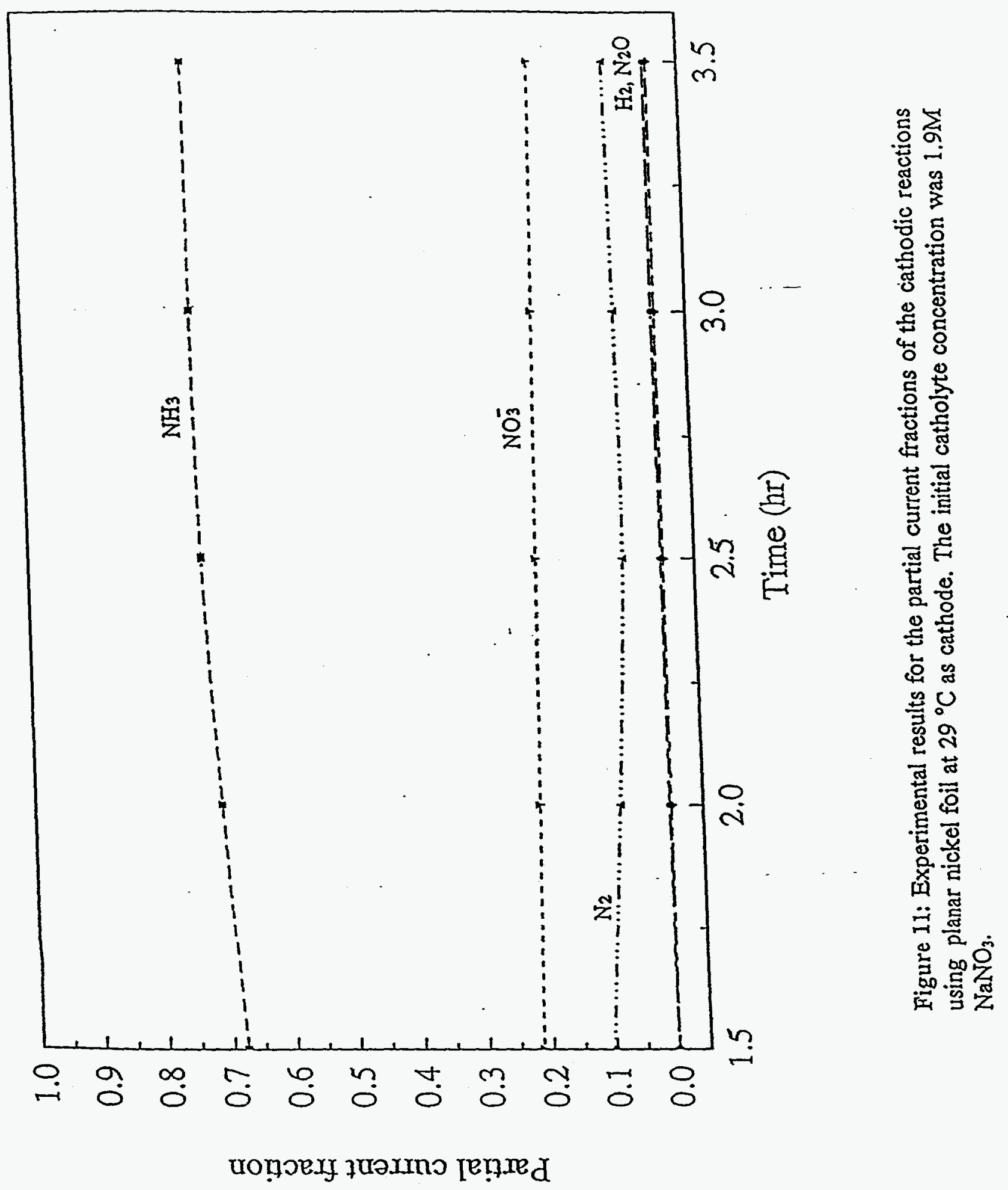




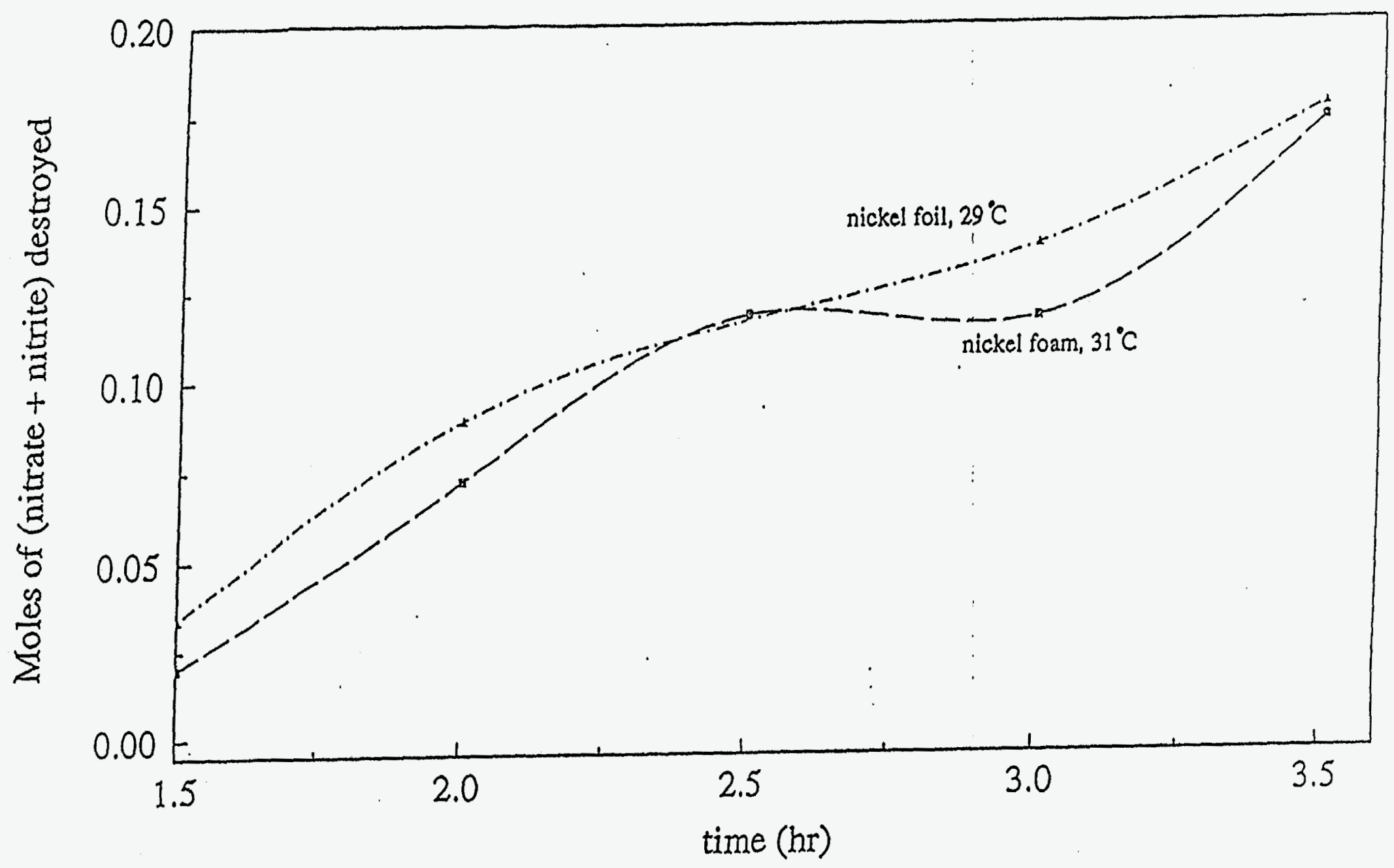

Figure 12: Moles of nitrate and nitrite destroyed for constant current runs using porous nickel foam, porous TySAR ${ }^{\mathrm{TM}} \mathrm{SB}$ and planar nickel foil as cathodes. The initial catholyte concentration was $1.9 \mathrm{M} \mathrm{NaNO}$ (traces of nitrite $\sim 0.02 \mathrm{M}$ were also present). The catholyte temperatures are shown on the plots. 


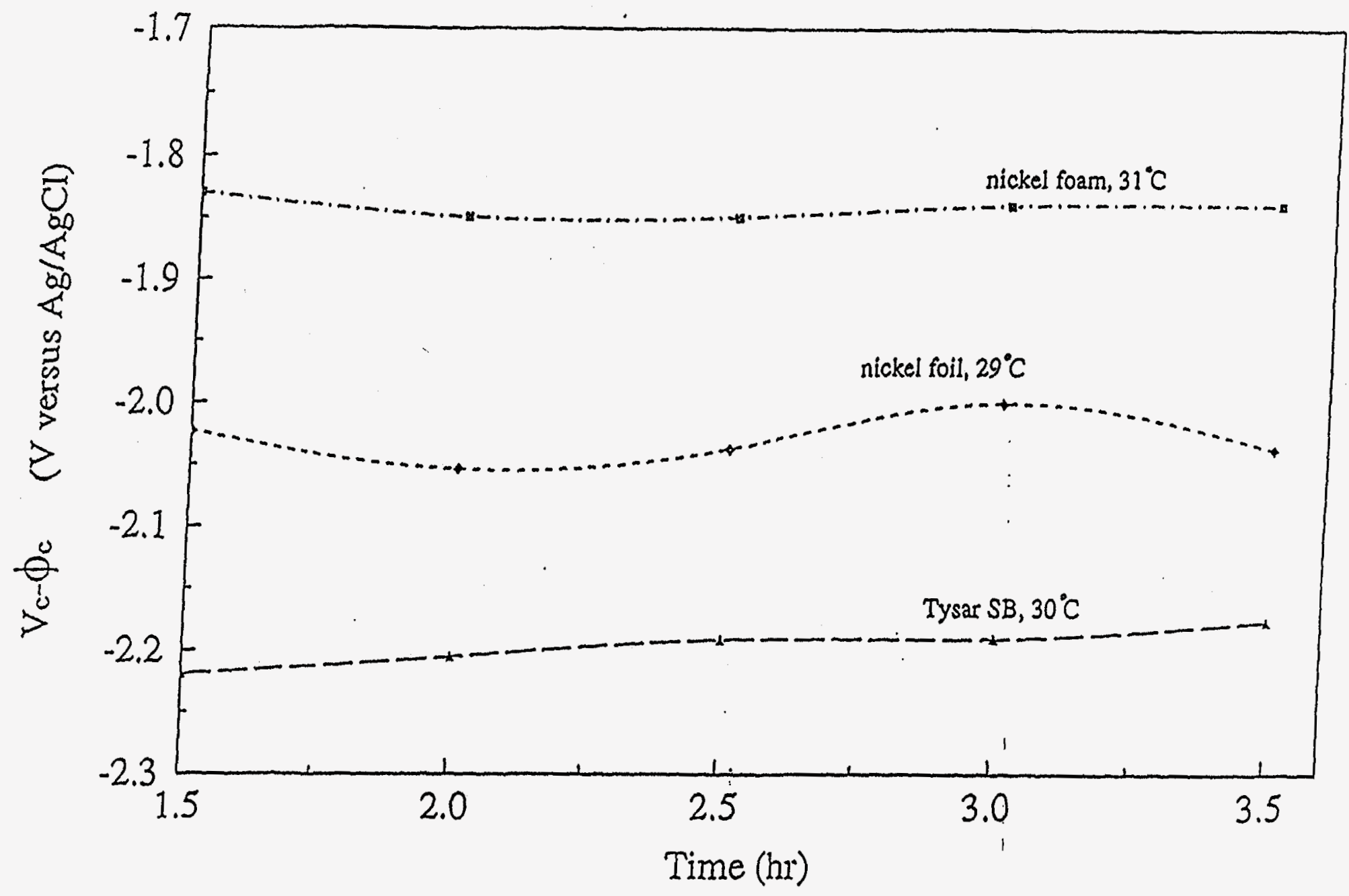

Figure 13: Cathodic overpotential needed for constant current runs using porous nickel foam, porous TySAR ${ }^{T M} S B$ and planar nickel foil as cathodes. The initial catholyte concentration was $1.9 \mathrm{M} \mathrm{NaNO}_{3}$. The catholyte temperatures are shown on the plots. 


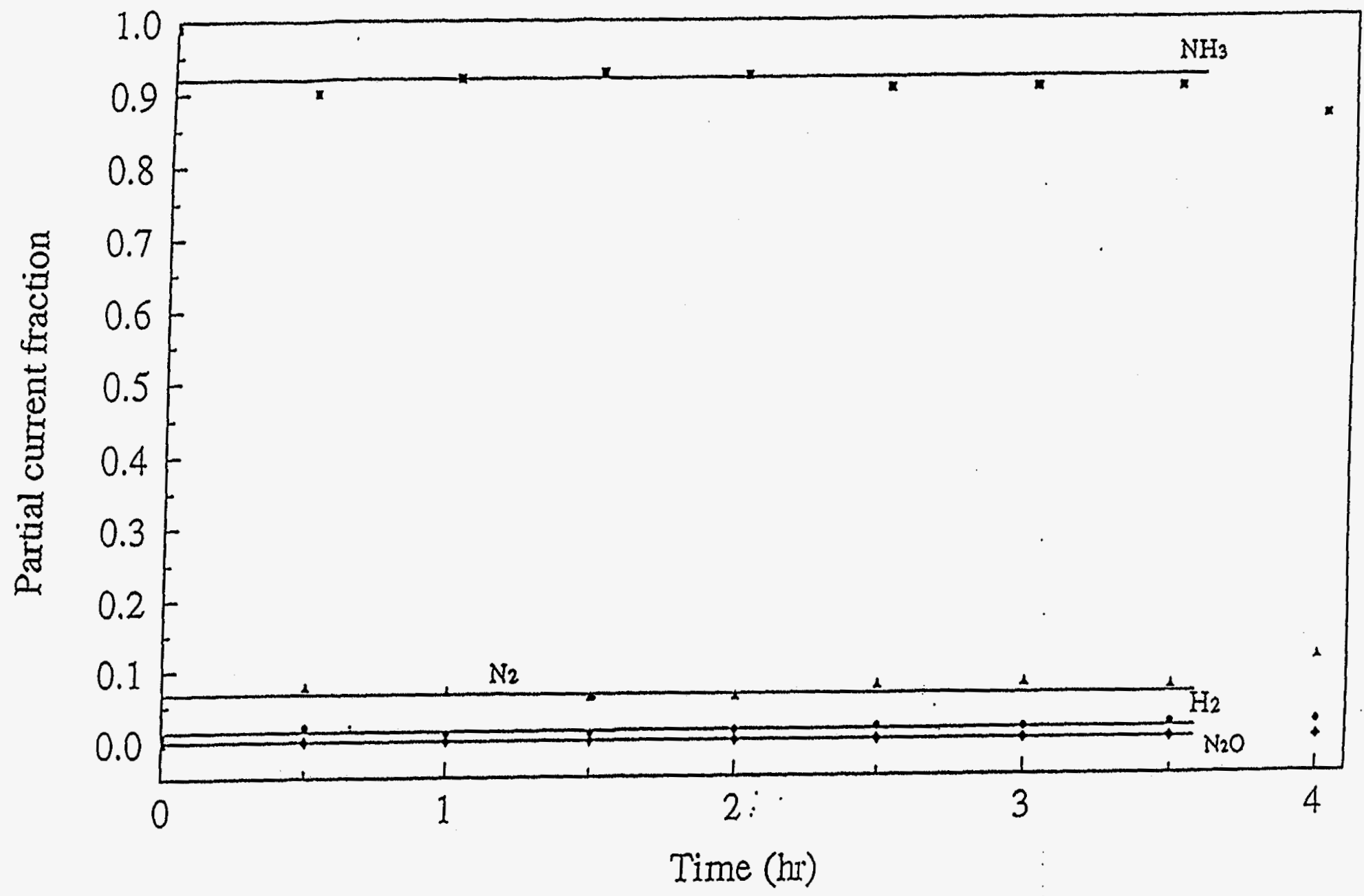

Figure 14: Comparison of the model predictions with the experimental results for the cathodic partial current fractions using porous nickel foam cathode at $32^{\circ} \mathrm{C}$. The solid lines represent the model predictions while the filled symbols are the experimental results. The kinetic parameters used for the model are as given in Table 4. The initial catholyte concentration was $0.6 \mathrm{M} \mathrm{NaNO}_{2}$. 


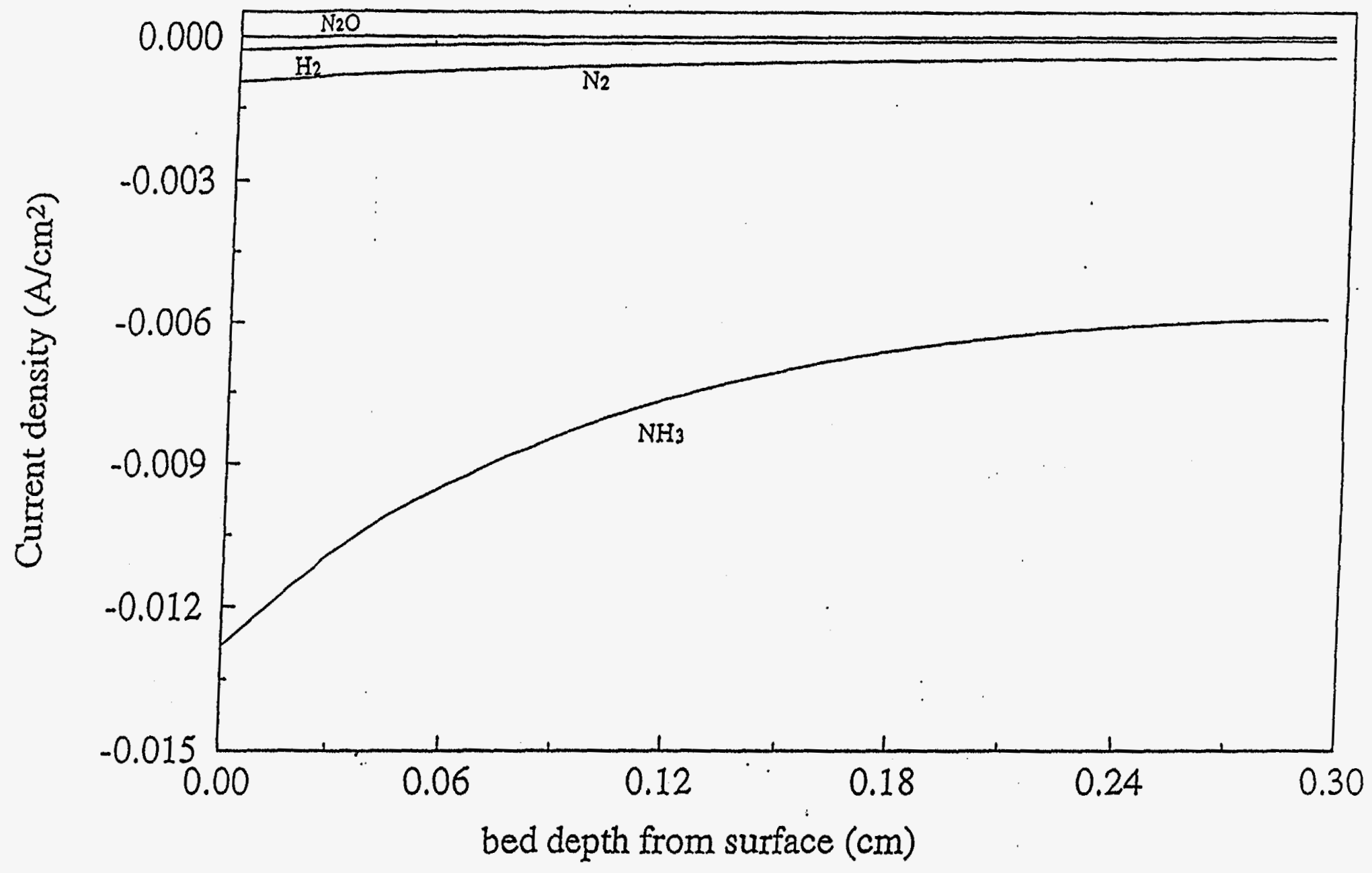

Figure 15: Steady state model simulation results for the axial profile of the reaction currents in a porous nickel foam cathode for a cell current of $25 \mathrm{~A}$. Catholyte concentration is $0.6 \mathrm{M} \mathrm{NaNO}_{2}$, temperature is $32{ }^{\circ} \mathrm{C}$ and the thickness of the cathode is $0.295 \mathrm{~cm}$. 


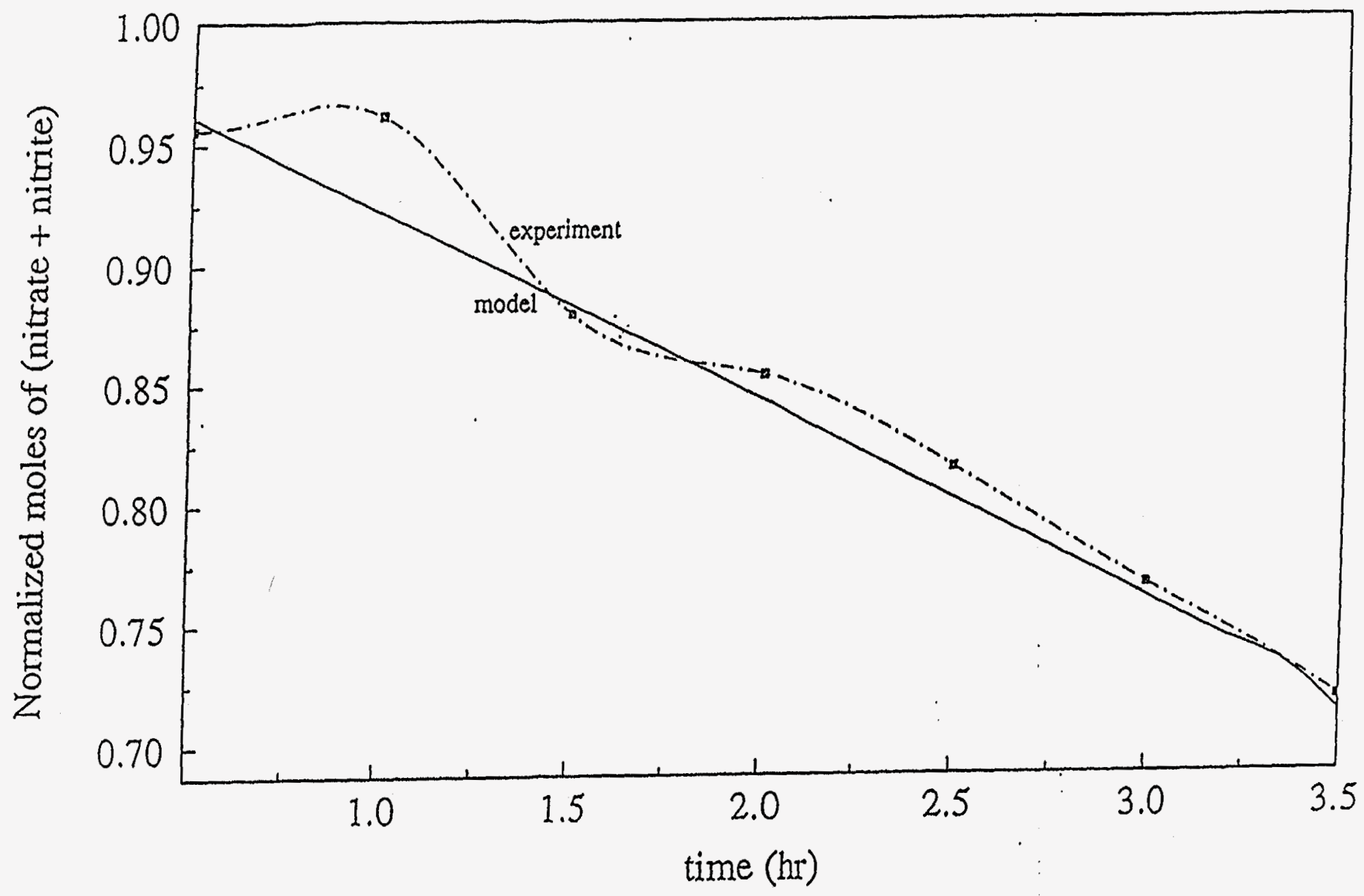

Figure 16: Comparison of the model predictions with the experimental results for the normalized modes of nitrate and nitrite destroyed using porous nickel foam cathode at 32 ${ }^{\circ} \mathrm{C}$. The moles are normalized with respect to the initial moles. The solid lines represent the model predictions while the dashed lines are spline fits to the experimental data points. The kinetic parameters used for the model are as given in Table 4. The initial catholyte concentration was $0.6 \mathrm{M} \mathrm{NaNO}_{2}$. 


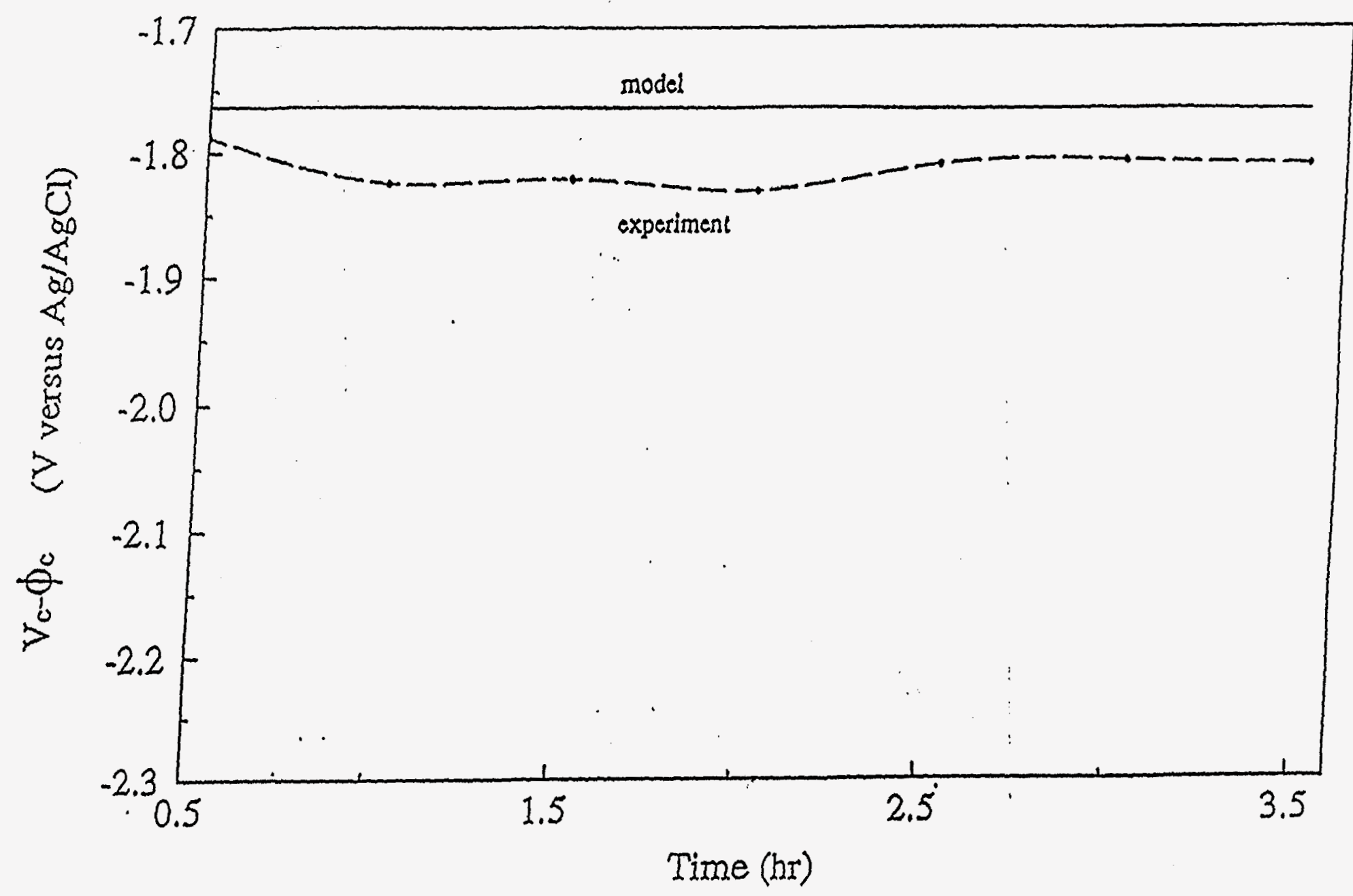

Figure 17: Comparison of the model predictions with the experimental results for the cathodic overpotential for porous nickel foam cathode at $32^{\circ} \mathrm{C}$. The solid lines represent the model predictions while the dashed lines are spline fits to the experimental data points. The kinetic parameters used for the model are as given in Table 4. The initial catholyte concentration was $0.6 \mathrm{M} \mathrm{NaNO}_{2}$. 


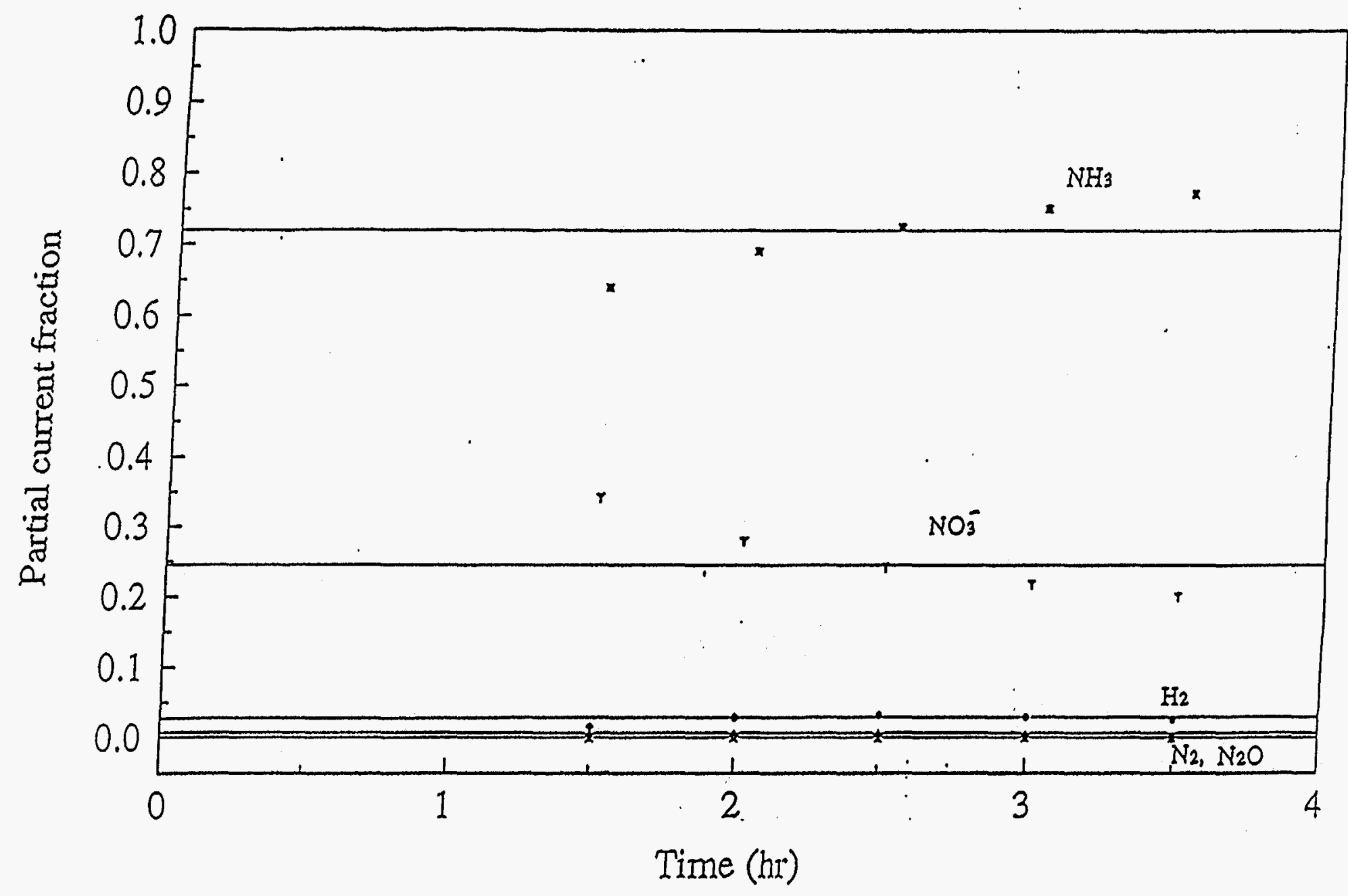

Figure 18: Comparison of the model predictions with the experimental results for the cathodic partial current fractions using porous nickel foam cathode at $31{ }^{\circ} \mathrm{C}$. The solid lines represent the model predictions while the filled symbols are the experimental results. The kinetic parameters used for the model are as given in Table 4 with the hydrogen exchange current density $\left(i_{0 s}\right)$ in parentheses being the value used. The initial catholyte concentration was $1.9 \mathrm{M} \mathrm{NaNO}_{3}$. 


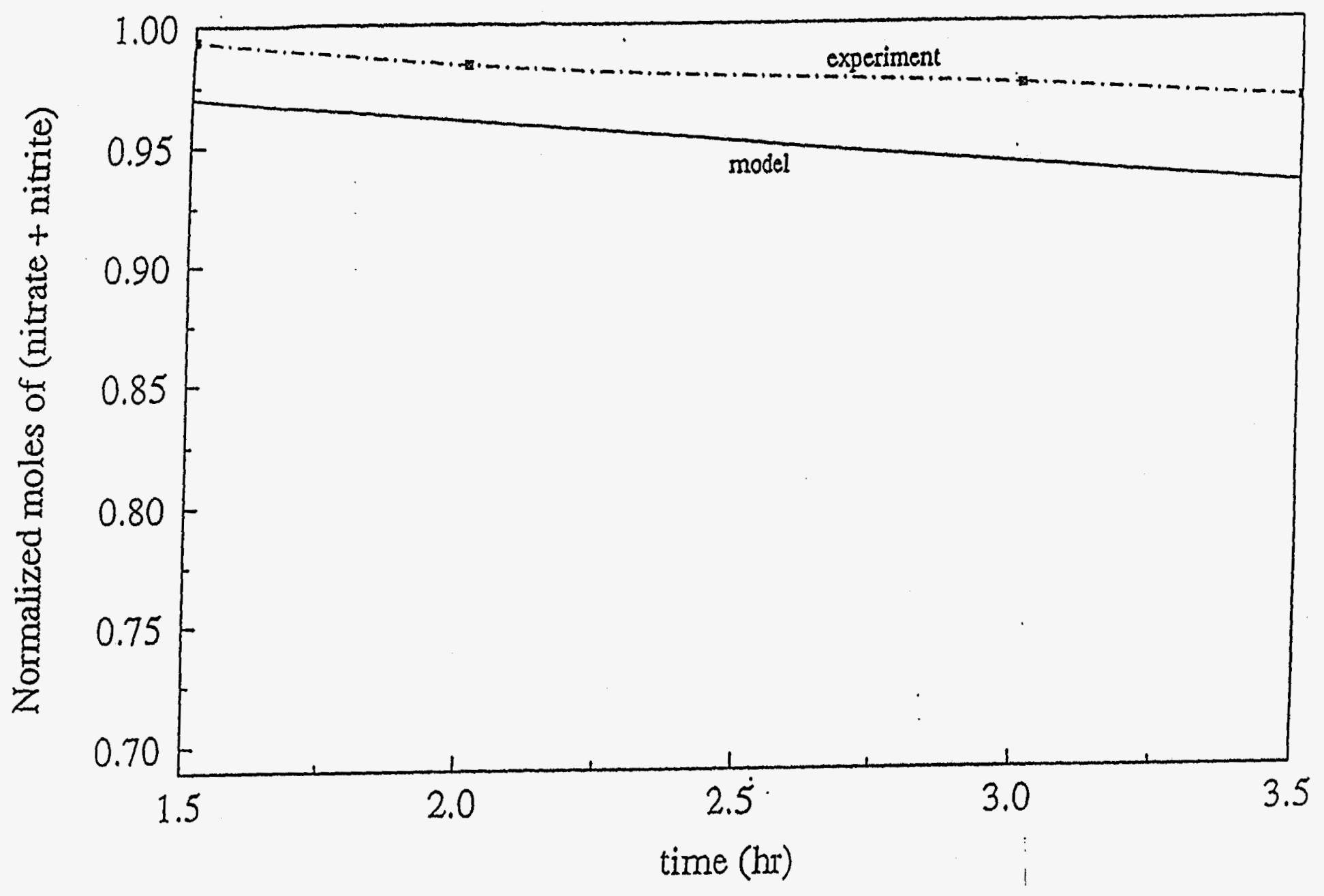

Figure 20: Comparison of the model predictions with the experimental results for the normalized modes of nitrate and nitrite destroyed using porous nickel foam cathode at 31 ${ }^{\circ} \mathrm{C}$. The moles are normalized with respect to the initial moles. The solid lines represent the model predictions while the dashed lines are a spline fit to the experimental data points. The initial catholyte concentration was $1.9 \mathrm{M} \mathrm{NaNO}_{3}$. 


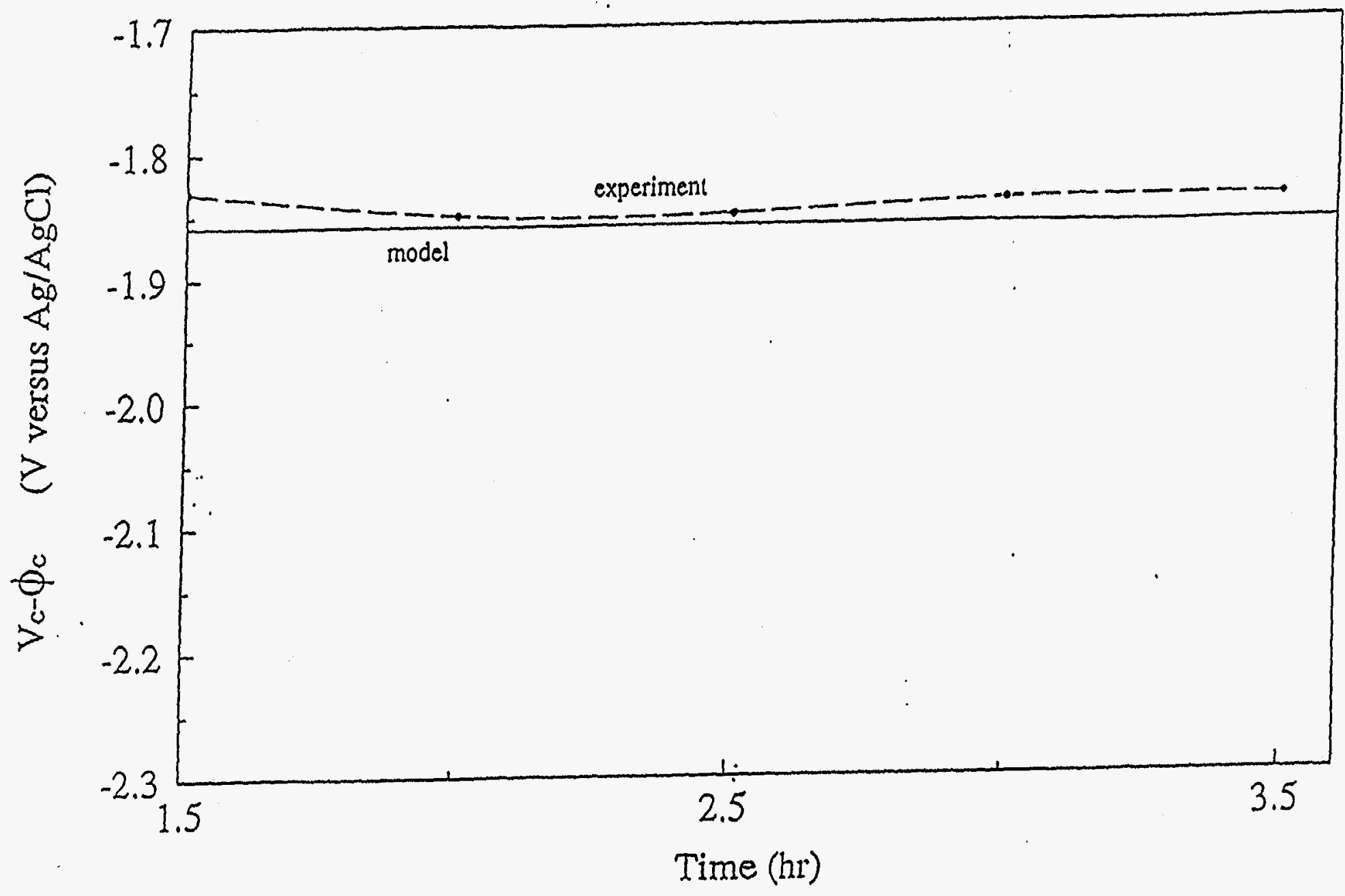

Figure 21: Comparison of the model predictions with the experimental results for the cathodic overpotential for porous nickel foam cathode at $31^{\circ} \mathrm{C}$. The solid lines represent the model predictions while the dashed lines are spline fits to the experimental data points. The initial catholyte concentration was $1.9 \mathrm{MNaNO}_{3}$. 


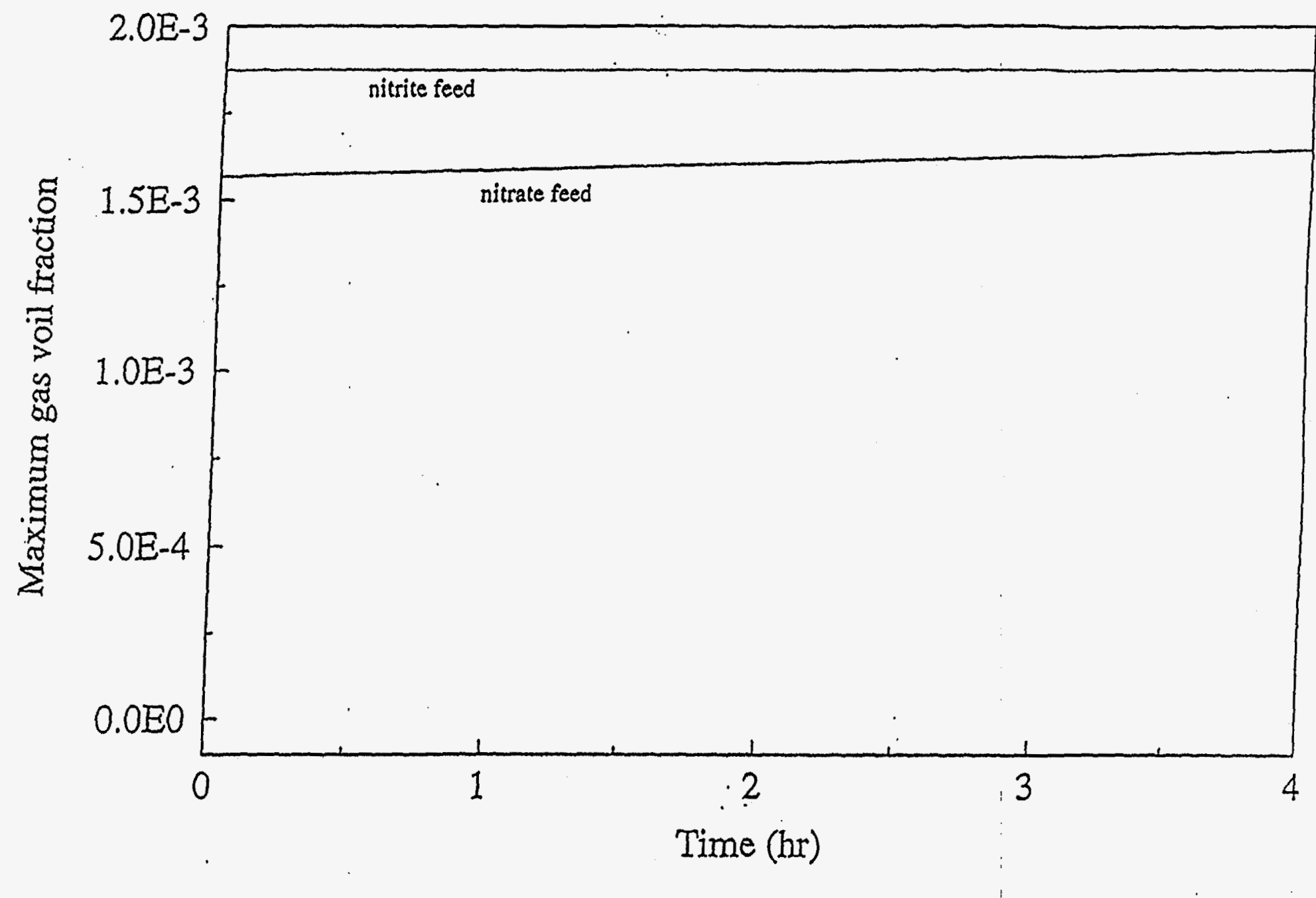

Figure 22: Comparison of the dynamic model simulation results for the maximum gas void fraction in a porous nickel foam cathode for a cell current of $25 \mathrm{~A}$ and using catholytes as: i) $1.9 \mathrm{M} \mathrm{NaNO}_{3}$, ii) ) $0.6 \mathrm{M} \mathrm{NaNO}_{2}$ at $31^{\circ} \mathrm{C}$. The thickness of the cathode is $0.295 \mathrm{~cm}$. Kinetic parameters values for the nitrite and nitrate catholyte are same for all the cathodic reactions except the hydrogen evolution reaction, where the value in parentheses in Table 4 is used for the nitrate system and the one outside parentheses for the nitrite system, 


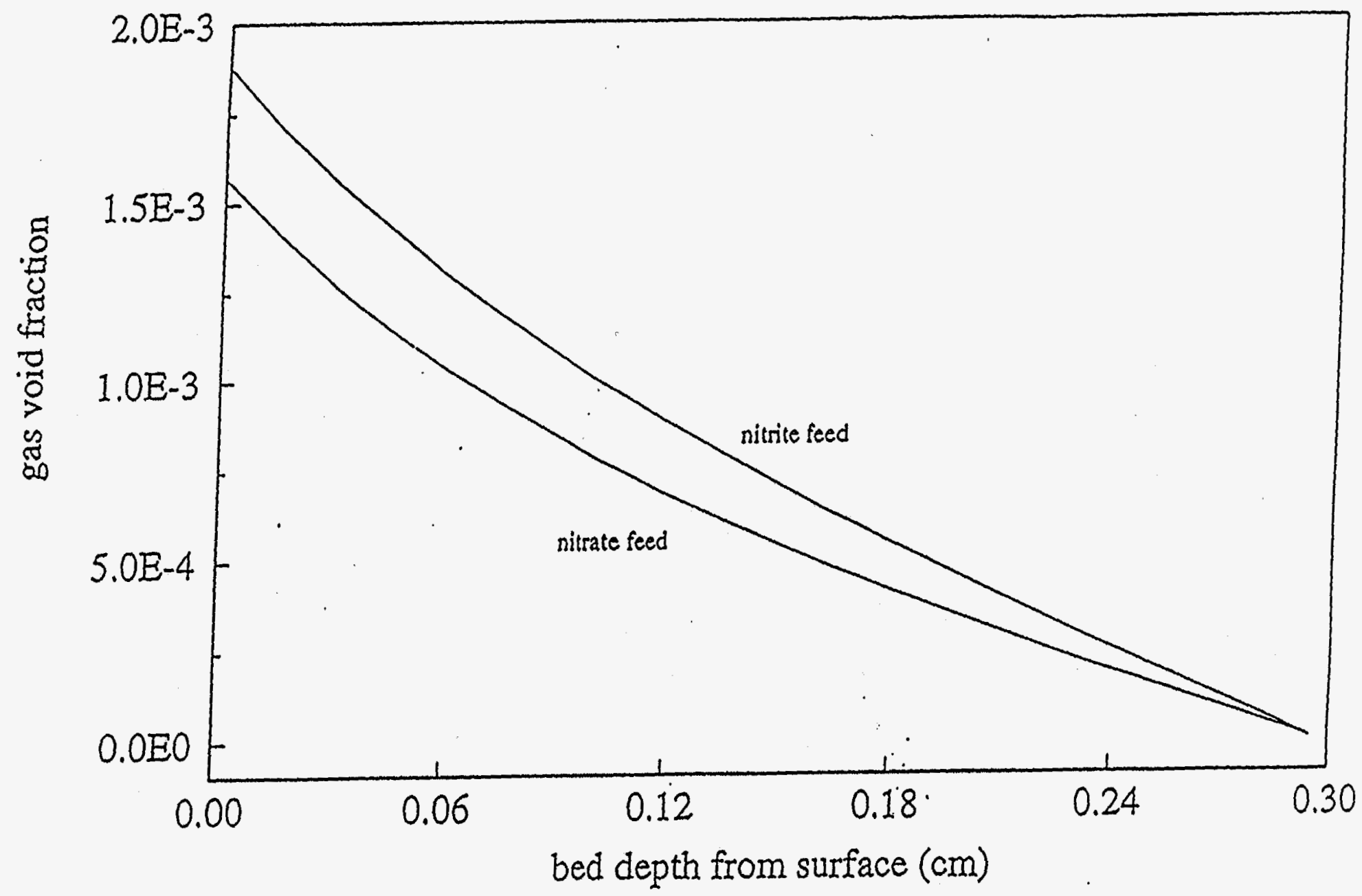

Figure 23: Comparison of the steady state model simulation results for the axial profile of the gas void fraction in a porous nickel foam cathode for a cell current of $25 \mathrm{~A}$ and using catholytes as: (i) $1.9 \mathrm{M} \mathrm{NaNO}_{3}$, (ii) $0.6 \mathrm{M} \mathrm{NaNO}_{2}$ at $31^{\circ} \mathrm{C}$. The thickness of the cathode is $0.295 \mathrm{~cm}$. Kinetic parameters are same as those used in Figure 22 . 